G.P.Battams and J.M. Dulieu-Barton, "Data-Rich Characterisation of Damage Propagation in Composite Materials", Composites Part A, 2016, doi:10.1016/j.compositesa.2016.08.007

\title{
Data-Rich Characterisation of Damage Propagation in Composite Materials
}

\section{G.P. Battams and J.M. Dulieu-Barton*}

University of Southampton

Faculty of Engineering and the Environment

*Corresponding author janice@soton.ac.uk

\begin{abstract}
A novel methodology for the synchronised capture of high resolution white-light and infra-red (IR) images during a fatigue test is described. The approach allows digital image correlation (DIC) and thermoelastic stress analysis (TSA) to be applied practically simultaneously without the requirement to pause the cyclic load. The methodology is demonstrated on cross-ply carbon-epoxy specimens that have experienced damage induced by intermediate strain rate loading. Similar undamaged specimens are studied and the results from each compared. Various damage types are identified which include transverse cracking, delaminations and longitudinal splitting. The results are verified using X-ray computed tomography (CT).
\end{abstract}

\section{KEYWORDS}

Polymer-matrix composites (PMCs), Damage tolerance, Fatigue, Optical techniques, Thermal analysis

\section{Introduction}

As the use of fibre-reinforced polymer (FRP) materials increases across a wide range of structural applications, damage tolerance to impact events and subsequent in-service performance of such materials is of paramount importance. Whilst the quasi-static behaviour of FRP materials has been generally well studied, e.g. [1], their behaviour at increased strain rates and during subsequent service life are less well defined [2], making damage-tolerant design challenging. Typical sources of high strain rate damage include a bird strike or hail impact on a wing leading edge, an explosive blast near a military vehicle or slamming encountered by small vessels in rough seas. It is therefore important to assess how FRP materials behave after a damage causing event to assess the degradation in structural performance. To do this, a controlled means of introducing damage at increased strain rate must 
G.P.Battams and J.M. Dulieu-Barton, "Data-Rich Characterisation of Damage Propagation in Composite Materials", Composites Part A, 2016, doi:10.1016/j.compositesa.2016.08.007

be defined. The damage must be such that the component can continue to carry load, enabling damage evolution to be monitored during subsequent fatigue loading, thus mimicking an inservice scenario.

A means of introducing controlled damage at intermediate strain rates to FRP coupon specimens loaded in tension by means of an Instron Very High Speed (VHS) servo hydraulic test machine has been devised. The test machine operates in open loop control and hence the actuator only stops when it has reached the end of its travel and the specimen has failed, not at a set displacement or load. Therefore an "interrupted loading methodology" has been developed [3] that utilises a specially designed loading rig to impart damage under tensile loading in the VHS machine without complete specimen failure. High speed infra-red thermography (IRT) and white-light imaging combined with digital image correlation (DIC) were used to assess the damage introduced to FRP coupon specimens during the intermediate strain rate event.

The main focus of the present paper is the development and validation of a novel methodology to assess damage evolution in composite components under fatigue type loading. A full-field imaging approach is defined that combines the digital image correlation (DIC) [4-6] and thermoelastic stress analysis (TSA) techniques [7] in a new way that enables data to be captured practically simultaneously. The motivation for combining the techniques is further insight into material behaviour than that provided by each technique alone. DIC is a white light optical technique that provides in-plane and out-of-plane surface displacements, from which the inplane normal and shear strains can be derived. DIC enables the identification of cracks and damage as discontinuities in the displacement and strain fields. TSA utilises an infra-red (IR) detector to obtain the temperature of the component under investigation. It relates the local change in temperature in a material to the change in applied stress (specifically the sum of principal stresses). As such, TSA only provides a stress metric, whereas DIC provides the component surface strains. Cracks and damage are identified because of the change in the stress distribution in the neighbourhood of the damage, characterised by a decrease in the thermoelastic response in the damaged region and an increase in the surrounding undamaged material. DIC enables the identification of cracks and damage as discontinuities in the displacement and strain fields. TSA has the advantage that, in general, data can be obtained at a much greater spatial resolution than DIC as each sensor point in the IR detector is a measuring point; DIC relies of a discretisation of the region of interest into 'subsets' or 'facets' that utilise the response from multiple sensors/pixels. Hence TSA is much more applicable to regions 
G.P.Battams and J.M. Dulieu-Barton, "Data-Rich Characterisation of Damage Propagation in Composite Materials", Composites Part A, 2016, doi:10.1016/j.compositesa.2016.08.007

where there are high stress gradients, e.g. in the vicinity of damage and cracks. TSA is not sensitive to out-of-plane displacement. By utilising a stereo (two-camera) DIC set-up, out-ofplane displacements can be identified and their effect accounted for in the in-plane strain values. The measurement of out-of-plane displacement enables better identification of any distortions caused by delaminations.

As the output from TSA is related to the sum of the principal stresses in an isotropic material a pure shear stress does not provide a thermoelastic response. In orthotropic materials, such as FRPs, the response is dependent on the coupling of coefficient of thermal expansions and the stresses [8]. Longitudinal to the fibres the coefficient of thermal expansion is small and transverse to the fibres the stress is small. This means that the thermoelastic response may also be small depending on the stress system, particularly in carbon reinforced plastic (CFRP) material. The response from a shear dominated system is therefore likely to be small making damage that results in a change in the shear stress difficult to distinguish. For instance, features like longitudinal splitting which causes a bundle of fibres to shear may go unnoticed in the thermoelastic response. On the other hand DIC can provide shear strains and can capture damage that causes shear. On the other hand, DIC cannot identify subsurface damage unless it has an effect on the surface strain, but TSA does allows some information to be inferred from subsurface laminae, mainly due to non-adiabatic effects. For instance, damage-induced heating at the onset of cracking or frictional effects between delaminated plies can be revealed as a result of the heat transfer. The use of the two techniques simultaneously therefore gives the ability to identify a greater number of damage types than either of the single technique alone and motivates the work developed in the present paper.

TSA naturally lends itself to fatigue damage assessments as a cyclic load is a requirement, as demonstrated in e.g. [9]. However DIC requires a correlation between two loaded states. The application of the two techniques practically simultaneously on the same surface during fatigue loading is new and the implementation of the approach requires significant novel design for image capture and data processing, which is described in detail in the paper. The outcome is that the surface strains from the DIC and stress metrics from the TSA are obtained during the fatigue cycling, thus providing further insight into the damage evolution process. Moreover, as images are collected as the damage occurs it is envisaged that the approach will provide a means of characterising damage types without the need to pause fatigue tests and carry out separate inspections. A further benefit is that such full-field imaging techniques can view an 
G.P.Battams and J.M. Dulieu-Barton, "Data-Rich Characterisation of Damage Propagation in Composite Materials", Composites Part A, 2016, doi:10.1016/j.compositesa.2016.08.007

entire specimen or component, hence a priori knowledge of the location of the onset of damage is not required.

DIC has been used to assess damage progression in glass reinforced polymer (GFRP) material under cyclic loading, e.g. [10, 11], where the images captured were under sampled and correlated with the cyclic load to reconstruct the overall strain change necessary to perform the DIC over a number of cycles. Likewise [9] is an example of where TSA has been used to evaluate fatigue damage progression. However, in the present work the aim is to capture both the IR data used for the TSA and the DIC data from a cyclically loaded specimen in a synchronised fashion without the need to pause the data collection. Chrysochoos and his coworkers, e.g. [12, 13], have conducted extensive research on thermomechanical material behaviour through the combination of DIC and IRT. The images for the DIC and IRT were collected from opposing sides of the specimen but to date, work has only been carried out on metallic specimens. Moreover, the data collection was not synchronised, only single camera DIC was used and the dissipative source was evaluated in most cases. Attempts to evaluate the thermoelastic source (i.e. the source that can be directly related to the stresses) are also described in [13], but have not been widely applied. The approach described in [12, 13] is not suitable for laminated FRP specimens because of their heterogeneous nature, which means it cannot be assumed that the material behaviour is identical on each face of the specimen. A method is therefore required for collecting white-light and IR images together from the same area of the specimen. This was achieved by Bodelot et al [14] in microscopic examinations of metallic materials by employing a dichroic mirror angled at $45^{\circ}$ to a specimen surface. A similar methodology was trialled for the present work to avoid the use of stereo DIC, but it was found that the tolerances in mirror flatness for observing larger regions of interest than that studied in [14] cause large image distortions; these could not be fully removed using the DIC calibration procedure. Therefore it was decided to use a calibrated stereo camera system to obtain images for DIC. It should be noted that in [14] quasi static loads were used and no attempt was made to extract the thermoelastic response.

There have been a few publications where TSA and DIC have been combined $[15,16]$ but not on data that has been captured together in a synchronised manner. In [15] white light images were captured separately and used to correct for the motion in the IR data to improve the accuracy of TSA. In [16] the failure mechanisms in an adhesively bonded joint were studied using single camera DIC and TSA. The DIC was conducted on images collected from quasi static tests and the IR data for the TSA was captured during a separate test using cyclic loading. 
G.P.Battams and J.M. Dulieu-Barton, "Data-Rich Characterisation of Damage Propagation in Composite Materials", Composites Part A, 2016, doi:10.1016/j.compositesa.2016.08.007

Both data sets were brought together at the same spatial resolution and the stress/strain distributions compared. An interesting paper by Silva et al, [17] uses IR data to conduct DIC for the purposes of correcting for motion in TSA data. This was facilitated by using paints of varying emissivity to create the speckle pattern. The IR images were processed using DIC and into thermoelastic data, which resulted in the simultaneous collection of thermal and kinematic data from various materials. Although this methodology allows for a simple experimental setup, the key advantage of using high resolution white-light cameras for DIC is lost. IR cameras have a much lower pixel counts and hence lower spatial resolution when compared to white-light devices, As a result, DIC data extracted from IR images will lack the spatial resolution necessary for damage identification, unless high magnification lens are used which demand $a$ priori knowledge of the damage location. In [18] stereo DIC, IRT and post mortem X-ray Computed tomography (CT) has been use to study damage evolution in quasi-static tests on CFRP materials. Here, the images for the DIC and the IRT were taken from same side of the specimen although the data collection was not synchronised. An element of cyclic loading was introduced but not in the sense of fatigue damage. Angle-ply and cross-ply woven carbon epoxy laminates were loaded using two routines; the first applies a quasi-static load to failure whilst the second is similar but returns the load to zero at several points during the quasi-static test. The author used a single IR camera positioned perpendicular to specimens to capture thermal data, whilst a stereo DIC system provided kinematic data. The mechanical test were paused so the specimens could be removed for X-ray CT to be carried out to verify damage type. From a load of $30 \%$ UTS onwards, thermal hotspots were identified as fibre breaks in the surface $0^{\circ}$ layer of crossply laminates. The resulting strain behaviour was found to be within the noise threshold of the DIC measurement and therefore could not be identified. Fibre-matrix debonding in angle-ply laminates could not be observed in the thermal images. This is attributed to the low energy release of this damage type and the homogenous distribution over the specimen surface. The results were very promising and demonstrated the feasibility of making coupled strain and temperature measurements, which has motived the work described in the present paper.

In the present paper, the full-field DIC/TSA imaging methodology is described and implemented on CFRP specimens. The damage propagation under fatigue loading is assessed, using specimens without prior damage and specimens that have experienced a controlled intermediate strain rate damaging event. X-ray CT is used to verify the damage types identified during the fatigue tests. 
G.P.Battams and J.M. Dulieu-Barton, "Data-Rich Characterisation of Damage Propagation in Composite Materials", Composites Part A, 2016, doi:10.1016/j.compositesa.2016.08.007

\section{Automated image capture methodology}

The TSA technique relies on an IR sensor to record small changes in surface temperature which occur due to an applied cyclic stress, known as the thermoelastic effect. The relationship between the small temperature change, i.e. the thermoelastic response, $\Delta T$, and the surface temperature, $T_{0}$, for orthotropic materials is expressed as follows [7]:

$$
\begin{aligned}
& \Delta T=-T_{0}\left(K_{1} \Delta \sigma_{1}+K_{2} \Delta \sigma_{2}\right) \\
& \text { where } \quad K_{1}=\frac{\alpha_{1}}{\rho C_{p}}, \quad K_{2}=\frac{\alpha_{2}}{\rho C_{p}}
\end{aligned}
$$

where $\alpha$ is the coefficient of thermal expansion, $\rho$ is the density, $C_{p}$ is the specific heat at constant pressure and $\Delta \sigma$ is the change in stress and the subscripts 1,2 indicate the principal material/laminae coordinates.

TSA is especially suited to the study of damage propagation as cyclic loading is required; hence data is captured without the interruption of a fatigue cycle. A series of thermal images are recorded synchronously with the load signal from the test machine during the cyclic loading. In the current work a CEDIP Silver 480M detector is used. The Altair-Li 5.90 software by CEDIP uses a lock-in algorithm to process IR images and the load signal from the test machine to obtain plots of $\Delta T, T_{0}$ and phase, where the phase is the lag between the applied stress change and $\Delta T$ [7]. Equation (1) is only valid if the thermoelastic response is in-phase or $180^{\circ}$ out-ofphase with the stress change. If any other phase difference exists in the thermoelastic response this indicates that localised plasticity, viscoelasticity or other nonlinear material behaviour is taking place. Moreover, equation (1) assumes that $\Delta T$ occurs isentropically [7], hence any heat transfer or other irreversible behaviour also results in a phase change. To ensure adiabatic conditions prevail it is usual to apply a cyclic loading frequency at a rate that minimises the thermal diffusion length. In laminated FRPs this is highly dependent on the resin and fibre materials, the ply thickness and the ply orientation; for CFRP material this has been suggested to be at least $15 \mathrm{~Hz}$ [19]. The CEDIP Silver 480M IR camera is capable of imaging full-frame (320 x 256 pixels) at a frequency of $383 \mathrm{~Hz}$, which is more than sufficient for sampling at loading frequencies up to $30 \mathrm{~Hz}$.

The DIC technique is performed on a set of pre-recorded digital images by tracking discrete areas of an image, known as cells. The surface under investigation requires a contrast pattern 
G.P.Battams and J.M. Dulieu-Barton, "Data-Rich Characterisation of Damage Propagation in Composite Materials", Composites Part A, 2016, doi:10.1016/j.compositesa.2016.08.007

to allow the correlation algorithm to successfully track the surface deformation. A detailed description of the DIC technique is given in e.g. [4-6].

The use of high speed white-light cameras to collect a series of images throughout a loading cycle to be later processed using DIC was considered, but the spatial resolution of images and hence the spatial resolution of the derived strain data would be reduced. A further benefit of using a methodology based around low-frame rate CCD cameras rather than high speed cameras is the decreased cost, allowing the methodology to be more accessible to future users.

An approach for DIC that utilises low-cost cameras and can be used during fatigue loading has been developed in [20], known as LIDIC (lock-in DIC), similar to that used in [10,11]. The approach captures a series of white-light images over multiple loading cycles. A lock-in correlation algorithm is applied in much the same way as TSA, but instead of mapping the response over the loading cycle by oversampling images, reconstructs the cyclic loading using DIC strain or displacement data extracted from undersampled images over multiple loading cycles. As the current work involves collecting many data samples over an extended fatigue cycle, the LIDIC method was not deemed suitable, both in terms of memory and postprocessing time. An alternative approach was therefore developed to obtain images at the point of maximum and minimum load using high resolution cameras. As the cameras have a low frame rate, accurate image timing and a short exposure time are necessary to capture images at exactly the peak load in a cycle and with minimal image blurring. A camera triggering and data collection system was developed in LabView 9.0 using a National Instruments USB-6211 data acquisition input/output device. The system allows the automatic and repeated capture of IR and white-light image data sets at pre-specified intervals in a fatigue test.

Figure 1 shows an overview of the test arrangement which comprises a CFRP specimen loaded in an Instron 8802 test machine, a NI USB-6211 device, two white-light cameras, a single IR camera and a zero-crossing detector circuit. The CEDIP Silver 480M IR camera was positioned nominally perpendicular to the specimen surface whilst being flanked by a set of two Manta G-504B 5 MPixel white-light cameras (manufactured by Allied Vision Technologies) set at an angle of approximately $60^{\circ}$ to the specimen surface. An overview of the camera settings is presented in Table 1. 
G.P.Battams and J.M. Dulieu-Barton, "Data-Rich Characterisation of Damage Propagation in Composite Materials", Composites Part A, 2016, doi:10.1016/j.compositesa.2016.08.007

Table 1: Summary of IR and white-light camera settings

\begin{tabular}{c|c|c|c|c|c|c} 
Camera & $\begin{array}{c}\text { Image size } \\
\text { (pixels) }\end{array}$ & $\begin{array}{c}\text { Specimen } \\
\text { imaging area } \\
\mathbf{( m m )}\end{array}$ & $\begin{array}{c}\text { Spatial } \\
\text { resolution } \\
\mathbf{( m m / p i x e l )}\end{array}$ & $\begin{array}{c}\text { Imaging } \\
\text { frequency } \\
\mathbf{( H z )}\end{array}$ & $\begin{array}{c}\text { Images captured } \\
\text { per sampling } \\
\text { point for each } \\
\text { camera }\end{array}$ & $\begin{array}{c}\text { Exposure/ } \\
\text { integration time } \\
\mathbf{( \mu s )}\end{array}$ \\
\hline $\begin{array}{c}2 \times \text { AVT } \\
\text { Manta G-504B }\end{array}$ & $2452 \times 2056$ & $19.96 \times 28.92$ & 0.014 & N/A & $\begin{array}{c}1 \text { at min load, } \\
1 \text { at max load }\end{array}$ & 900 \\
\hline $\begin{array}{c}1 \text { x CEDIP } \\
\text { Silver 480M }\end{array}$ & $320 \times 256$ & $19.96 \times 67.23$ & 0.261 & 383 & 600 & 1300
\end{tabular}

The Instron 8802 servo-hydraulic test machine applied a constant cyclic load $(P)$ to FRP specimens (as shown in Figure 2). The machine was set to operate in 'load control' mode so that the applied load range and mean load remained constant throughout the test, regardless of damage evolution in the FRP specimen. The machine was set to operate with amplitude control off to ensure maximum accuracy in the frequency of the cyclic loading. The load voltage output was offset to remove the effect of mean load, such that the cyclic load voltage varied about 0 $\mathrm{V}$. This is necessary for the zero crossing detector to function, as described below.

A LabView script was devised and implemented to count the loading cycles via the analogue inputs of the USB-6211 device. A loading cycle was recorded each time a change in gradient was detected within the smoothed load signal. When the number of loading cycles reached a requested sampling point, the IR camera was triggered by a 5V TTL (transistor-transistor logic) pulse to begin the recording of an IR video, consisting of 600 images for later TSA lock-in processing, as shown schematically in Figure 2. Using the TTL pulse to trigger the white-light cameras is not appropriate as the run time of the code was found to be highly variable, resulting in image sets being captured at an arbitrary point within a loading cycle. For the strain data to be comparable between successive data sets, images must be captured at the maximum and minimum of the loading cycle as shown in Figure 2.

A simple zero-crossing detector circuit was developed as an extension to the system to aid the triggering of the Manta cameras and avoid the inherent timing inaccuracies when running multiple software on a single PC. Figure 3 shows the zero crossing detector circuit producing positive square pulses where the test machine load signal falls below $0 \mathrm{~V}$ (i.e. the mean load). The device constantly supplies square pulses to the white-light cameras (as shown in Figure 1) whilst the fatigue tests is ongoing, however, the cameras only become receptive to the signal when instructed by the LabView code. At a requested sampling point in the fatigue test, the instruction is sent to the white-light cameras to wait for the next rising edge from the zero- 
G.P.Battams and J.M. Dulieu-Barton, "Data-Rich Characterisation of Damage Propagation in Composite Materials", Composites Part A, 2016, doi:10.1016/j.compositesa.2016.08.007

crossing detector. This occurred typically within 8 cycles after the start of the IR image collection, dependent on the speed of the PC, i.e. within the IR imaging period. By specifying a fixed delay before camera exposure after receipt of the rising edge based upon the loading frequency, the two images for the stereo DIC can be consistently captured with the image exposure centred at the point of minimum load. The procedure is repeated with a greater delay to capture a further set of stereo images at the point of maximum load, which, typically occurred within 26 cycles after the start of IR image collection. The stereo image sets are therefore captured approximately 3.63 seconds (18 loading cycles) after the end of IR data capture. The hardware based method eliminates the previously mentioned timing uncertainties resulting from software, and the fact that the second DIC image set may be captured after the IR data collection is complete has little effect on the results. As shown in Figure 3, a separate oscilloscope trace was used to validate the methodology. Over a trial of 20 attempts the methodology was found to give a worst case image timing of 0.773 ms away from the true maximum load point, equivalent to the capture of an image at $99.8 \%$ of the maximum load at an applied loading frequency of $10 \mathrm{~Hz}$.

To deal with short exposure times (see Table 1) and hence reduced excitation of the white-light sensors, a high intensity light emitting diode (LED) lighting system was developed using an array of 8 Intelligent LED Solutions ILH-ON01-ULWH-SC201 modules. Each LED module, outputting approximately 250 lumens, was combined with an acrylic lens of a full-width half maximum angle of $4.5^{\circ}$ giving a concentrated column of visible light directed on the FRP specimen. The system produces minimal IR output when compared to halogen-type illumination. It also provides a constant light source, in contrast to many off-the-shelf LED lighting units which use pulse modulation of the supply voltage to control the LEDs, resulting in variable lighting conditions when imaged at high frequency or when using short exposure times.

\section{Test specimen preparation}

All test specimens studied were of a symmetrical crossply lay-up, as shown in Figure 4. The damage behaviour of crossply material has been extensively documented [1, 21-23], helping to simplify the interpretation of optical measurements. The use of crossply material also avoids complicating effects arising from elastic coupling. As TSA and DIC are considered to be surface techniques, an outer $90^{\circ}$ ply was used to promote surface damage early in the specimen 
G.P.Battams and J.M. Dulieu-Barton, "Data-Rich Characterisation of Damage Propagation in Composite Materials", Composites Part A, 2016, doi:10.1016/j.compositesa.2016.08.007

fatigue life in the form of transverse cracking. Clearly if a different ply lay-up is used a different form of damage will evolve, so for the study described here, which aims to demonstrate the methodology, a [90, 0]s lay-up was used to ensure some surface damage occurred.

Four layers of Gurit SE84LV unidirectional carbon epoxy pre-preg material were used to give a [90, 0]s lay-up and a panel thickness of $1.13 \mathrm{~mm}$ (i.e. a ply thickness of about $0.28 \mathrm{~mm}$ ). Specimens were produced from the panels of $20 \mathrm{~mm}$ nominal width and $100 \mathrm{~mm}$ nominal gauge length. End tabs were incorporated with the laminate during lay-up and cure as these have been shown to possess superior interfacial strength compared to conventional adhesively bonded end tabs [24]. The use of the end tabs is particularly important for the specimens that were damaged using the intermediate strain rate loading. A summary of the experimentally derived specimen material properties is provided in Table 2.

\section{Table 2: CFRP specimen material properties}

\begin{tabular}{l|c|c|c|c|c}
\multirow{2}{*}{ FRP material } & \multirow{2}{*}{$\begin{array}{c}\text { Stacking } \\
\text { Sequence }\end{array}$} & \multicolumn{2}{|c|}{$\begin{array}{c}\text { Quasi-static properties } \\
\left(\mathbf{0 . 0 0 0 3} \mathbf{~ s}^{-1}\right)\end{array}$} & \multicolumn{2}{c}{$\begin{array}{r}\text { Intermediate strain rate } \\
\left(\mathbf{S 2 ~ s}^{-\mathbf{1}}\right)\end{array}$} \\
\cline { 3 - 6 } & & Young's Modulus & UTS & Young's Modulus & UTS \\
\hline \hline $\begin{array}{l}\text { Carbon-Epoxy } \\
\text { Gurit SE84LV }\end{array}$ & {$[90,0]_{\mathrm{S}}$} & $71.20 \pm 1.31 \mathrm{GPa}$ & $951 \pm 28 \mathrm{MPa}$ & $66.17 \pm 2.95 \mathrm{GPa}$ & $1073 \pm 60 \mathrm{MPa}$
\end{tabular}

CFRP specimens were coated in two passes of RS matt black paint followed by a light coat of Ambersil matt white paint to create a speckle pattern suitable for DIC analysis. Speckle patterns applied to specimens previously loaded using the interrupted loading methodology were removed using acetone, prior to the application of a finer speckle pattern, more suited for DIC analysis using high resolution white-light cameras. This is because the spatial resolution of the high resolution cameras is greater than that of the high speed cameras and hence a finer speckle pattern ensures that there is sufficient uniqueness in a DIC subset [25]. Examination using an optical microscope showed that the paint coating thickness varied between 15 and $40 \mu \mathrm{m}$. The large variation of paint thickness is due to the surface roughness of the material; an artefact of the peel-ply fabric required during manufacture. No difference in IR response could be noted as a result of the applied speckle pattern as confirmed in [15].

\section{Introduction of intermediate strain rate damage}


G.P.Battams and J.M. Dulieu-Barton, "Data-Rich Characterisation of Damage Propagation in Composite Materials", Composites Part A, 2016, doi:10.1016/j.compositesa.2016.08.007

An Instron VHS test machine was used to impart the intermediate strain rate loading into some of the CFRP specimens. A 'slack adaptor' gripping system has been developed so that the actuator can accelerate to a constant velocity before clamping the specimen and applying load. The actuator inertia and hence absence of feedback in the control system means that the actuator only stops at the end of its travel and not at a predefined displacement or load. The result is that the specimen generally always fails when loaded in tension, making it impossible to impart a known load that merely damages the specimen. Therefore some specialist modifications to the VHS test machine are required to apply loading to a predefined value, thus producing specimens that contain damage but are still intact and can carry further loads. To this end, the interrupted loading rig was developed to be used in the Instron VHS test machine, which allows load to be imparted without complete specimen failure.

Figure 5 shows the interrupted loading rig, which comprises an aluminium 6082-T6 shear pin, notched at two locations using a $1 \mathrm{~mm}$ radius tool designed to fail at a load less than the specimen failure load. The load imparted on the specimen is varied by altering notch depth. After shear pin failure, the lower grip and connected parts recoil upwards due to stored strain energy in the FRP specimen, so causing compressive loading and potentially additional damage. As FRP materials are more susceptible to damage from compressive loads, a static preload was applied to specimens prior to a test using an adjustable crossbar, ensuring that specimens remain in tension throughout a test. The preload was determined via strain gauges mounted on the specimen surface. The methodology is described in detail in Chapter 7 of [3].

The interrupted loading rig was used to apply a dynamic load of $10.6 \mathrm{kN}$ at a nominal strain rate of $32 \mathrm{~s}^{-1}$ to specimens. When combined with a $6.6 \mathrm{kN}$ preload, the total peak applied load is equivalent to $72 \%$ of the material ultimate tensile strength (UTS). IR images where captured with the CEDIP Silver system using the adaptations described in [26] to obtain the IR images at high frame rates. White-light images for DIC were captured with 2 Photron SA1 cameras. The settings for both camera systems used during the tests are given in Table 3. To achieve frame rates above $383 \mathrm{~Hz}$, the IR detector must be windowed resulting in a reduced array size. The stand-off distance of the IR camera was altered to achieve a spatial resolution a factor of 10 less than that of the white-light images.

Table 3: Imaging settings for intermediate strain rate tests

\begin{tabular}{l|c|c|c|c|c} 
Camera & $\begin{array}{c}\text { Image Size } \\
(\text { pixels })\end{array}$ & $\begin{array}{c}\text { Image Size } \\
(\mathrm{mm})\end{array}$ & $\begin{array}{c}\text { Spatial } \\
\text { Resolution } \\
(\mathrm{mm} / \text { pixel })\end{array}$ & $\begin{array}{c}\text { Frame rate } \\
(\mathrm{Hz})\end{array}$ & $\begin{array}{c}\text { Exposure/ } \\
\text { Integration time } \\
(\mu \mathrm{s})\end{array}$ \\
\hline
\end{tabular}


G.P.Battams and J.M. Dulieu-Barton, "Data-Rich Characterisation of Damage Propagation in Composite Materials", Composites Part A, 2016, doi:10.1016/j.compositesa.2016.08.007

\begin{tabular}{c|c|c|c|c|c}
\hline \hline CEDIP Silver 480M & $64 \times 24$ & $21.12 \times 7.92$ & 0.330 & 9372 & 80 \\
\hline 2 x Photron SA1 & $624 \times 448$ & $20.33 \times 14.60$ & 0.033 & 18000 & 55.6
\end{tabular}

DIC was performed on the white light images using Davis 8.0 with respect to a reference image of the unloaded specimen. IR surface temperature data was processed using a thresholding algorithm, in which any pixel found to increase rapidly in temperature between subsequent frames (indicative of local heating and damage) was retained in the final image. A threshold value of $0.5^{\circ} \mathrm{C}$ was found to be the best compromise of sensor noise suppression whilst retaining any surface temperature rise data. It should be noted that the specimen moves as the test progresses but the IR detector remains stationary. Hence the location of the temperature evolution is captured by different sensors in the IR detector array. To produce an image that is not blurred this must be corrected for, so a Matlab script was developed using the surface displacements obtained from DIC to correct the IR data. It is necessary to establish a datum that is visible in the IR and white-light images. This was done prior to each test using a small piece of wire attached to the specimen surface which is visible in both white-light and IR images. Since the spatial resolutions of the two data types are different, the locations of the DIC and IR data are not coincident. A bilinear interpolation method was used similar to that described in [15] to resample the DIC displacement data at the IR pixel locations, so allowing the IR data to be shifted to track the deformation of the surface and allowing the two data types to be compared. This procedure was repeated iteratively for each image collected. An example of such data is shown in Figure 6, where multiple bands of high strain coincide with the bands of thermal activity. It was of primary concern to determine that the bands shown were the result of material damage rather than cracking of the paint coating, camera fill factor [27], or systematic subpixel interpolation errors in the DIC algorithm [28], all of which can result in 'banding' in the DIC image. Although the thermal activity provided additional confidence that the banding was not a result of the latter two, as it probably can be attributed to irreversible heating effects resulting from the cracking, it does not rule out cracking of the paint coating as a potential cause. Sectioning and optical microscopy of specimens identical to the ones tested subsequently showed that the response in both the DIC and thermal images coincided with transverse cracks in the outer $90^{\circ}$ lamina and were not the result of cracking in the surface paint layer alone. Therefore it can be concluded that the surface damage generated by the interrupted load is in the form of transverse cracking. 
G.P.Battams and J.M. Dulieu-Barton, "Data-Rich Characterisation of Damage Propagation in

Composite Materials", Composites Part A, 2016, doi:10.1016/j.compositesa.2016.08.007

\section{Fatigue tests}

Prior to performing a fatigue test, a stereo set of white-light images were captured of the specimen at zero applied load. These images were subsequently used as the reference images during DIC analysis such that all strain data is related to the maximum load experienced by the specimen; the TSA data is a function of the cyclic load range.

As the specimen is cyclically loaded it is also necessary to account for the effects of rigid-body motion on TSA [15]. Rigid body motion during the recording of an IR video is detrimental to TSA analysis as the incident IR radiation of an individual pixel becomes a combination of the original sampling area and surrounding areas. Example data showing the importance of motion compensation on the thermoelastic response is shown in Figure 7. Motion compensation was therefore carried our using the 'Random Motion' 5.90 software by CEDIP. The software requires the use of tracking points that are visible in the IR images. The most suitable method for producing tracking markings on the specimen surface was therefore investigated. Markings produced using Tippex, pencil lead, ball-point pen and self-adhesive aluminium foil were trialled, as shown in Figure 7. Self-adhesive aluminium foil markings were found to give the highest IR contrast and the most stable video after motion compensation and were therefore applied to all specimens before testing. The self-adhesive aluminium foil was found to remain well adhered to the specimen surface even after the application of in excess of one million loading cycles.

For reliable TSA data, a cyclic load must be applied at sufficient frequency to ensure adiabatic conditions prevail. A CFRP specimen was cyclically loaded at $109 \pm 87.7 \mathrm{MPa}$ over a range of loading frequencies. The specimen was imaged using the IR camera and the resulting set of videos processed using the Altair-Li 5.90 software. The resulting plots of $\Delta T$ data were averaged across the entire specimen area and plotted against loading frequency as shown in Figure 8. The CFRP specimen tends towards a $\Delta T$ value of $0.162{ }^{\circ} \mathrm{C}$ at frequencies above approximately $4 \mathrm{~Hz}$, much lower than the quoted minimum of $15 \mathrm{~Hz}$ [19] because of the thick plies used in the lay-up, signifying adiabatic conditions were achieved at this loading frequency. Based on these trials, the cyclic loading frequency was $5 \mathrm{~Hz}$ for all tests conducted. All specimens were loaded using the conditions given in Table 4.

\begin{tabular}{|c|c|c|c|c|c|c|}
\hline \multirow{2}{*}{ Specimen } & \multirow{2}{*}{$\begin{array}{l}\text { Mean } \\
\text { Stress }\end{array}$} & \multirow{2}{*}{$\begin{array}{l}\text { Cyclic Stress } \\
\text { Amplitude }\end{array}$} & \multirow{2}{*}{ Frequency } & \multirow{2}{*}{$\begin{array}{l}\text { Loading } \\
\text { Cycles }\end{array}$} & \multicolumn{2}{|c|}{ Data collection intervals } \\
\hline & & & & & $<10000$ cycles & $>10000$ cycles \\
\hline$[90,0]_{s}$ CFRP & $300 \mathrm{MPa}$ & $270 \mathrm{MPa}$ & $5 \mathrm{~Hz}$ & 250000 & Every 500 cycles & Every 5000 cycles \\
\hline
\end{tabular}


G.P.Battams and J.M. Dulieu-Barton, "Data-Rich Characterisation of Damage Propagation in Composite Materials", Composites Part A, 2016, doi:10.1016/j.compositesa.2016.08.007

Table 4: Fatigue loading conditions for CFRP specimens

\section{Data processing and presentation}

A total of 66 data sets were collected during the fatigue loading of each CFRP specimen, at the intervals specified within Table 4. Each data set comprises a stereo set of white-light images at the maximum load point, a stereo set of white-light images at the minimum load point, test machine data (load amplitude, mean load etc.) and a video of 600 IR images captured at 383 $\mathrm{Hz}$ (1.57 seconds duration), see Table 1. The white light images were processed with DaVis 8.1.3 by LaVision using a cell size of 31 x 31 pixels and a step size of 6 pixels. To compute the subset displacement to greater accuracy, grey levels values are evaluated at subpixel locations using an interpolation method and the LSM method repeated in an iterative manner [29]. A $6^{\text {th }}$ order spline interpolation method was used for greater accuracy in displacement vectors at the cost of greater computation time. The IR videos were motion compensated using the 'Random Motion’ software as discussed above and processed into TSA data using Altair LI 5.90.

Maps of longitudinal $\left(\varepsilon_{y y}\right)$, horizontal $\left(\varepsilon_{x x}\right)$ and shear strain $\left(\varepsilon_{x y}\right)$ were obtained using DIC for each of the data sets collected. Maps of thermoelastic temperature change $(\Delta T)$, mean temperature $\left(T_{0}\right)$ and phase were obtained for each of the sets of IR data collected during the fatigue test. As mentioned above, the phase data identifies regions where $\Delta T$ is not in-phase with the stress change. In FRP materials, these out of phase regions may indicate areas of subsurface heating caused by frictional effects between plies after a delamination occurs, which then conducts to the surface. $\Delta T$ values were divided by the mean temperature $T_{0}$ at each pixel location to give a normalised thermoelastic response $\left(\Delta T / T_{0}\right)$. Expressing the thermoelastic response in the form $\Delta T / T_{0}$ is useful as it makes account of any changes due changes in room temperature or because of localised heating at damage sites [9], but not heat transfer. $K_{1}$ and $K_{2}$ were not evaluated as they are coupled with the stresses (see equation (1)) and it is not possible to extract these directly from the $\Delta T / T_{0}$ data. Therefore the $\Delta T / T_{0}$ is an important 'stress metric' related to the stress change and redistribution as the damage evolves. The normalised thermoelastic data maps were further processed to investigate how the thermoelastic response of each pixel changes with time using the formula:

$$
\Delta\left(\frac{\Delta T}{T_{0}}\right)=\left(\frac{\Delta T}{T_{0}}\right)_{n}-\left(\frac{\Delta T}{T_{0}}\right)_{n-1}
$$

where $\Delta T$ is the thermoelastic temperature change, $T_{0}$ is the mean temperature and $n$ is the data set number. 
G.P.Battams and J.M. Dulieu-Barton, "Data-Rich Characterisation of Damage Propagation in Composite Materials", Composites Part A, 2016, doi:10.1016/j.compositesa.2016.08.007

Six data types were derived for each image capture, i.e. longitudinal $\left(\varepsilon_{y y}\right)$, transverse $\left(\varepsilon_{x x}\right)$, shear strain $\left(\varepsilon_{x y}\right), \Delta T / T_{0}, \Delta\left(\Delta T / T_{0}\right)$ and the TSA phase data. In total 66 data sets were analysed for each specimen. Due to the amount of image data collected and the derived data types the following two sections show example data only where interesting features appear indicating damage growth. All image data types shown in the following sections have the specimen dimensions indicated on the image vertical and horizontal scales in $\mathrm{mm}$.

\section{Undamaged specimen}

Two undamaged CFRP specimens were loaded as stated in Table 4 and imaged using the methodology described above. Similar features were found to occur in the derived data types at similar instances during the tests. Figure 9 shows the longitudinal strain $\left(\varepsilon_{y y}\right)$ and normalised thermoelastic response $\left(\Delta T / T_{0}\right)$ from the first data set collected, after approximately 10 loading cycles. The horizontal bands of high longitudinal strain coincide with bands of decreased thermoelastic response. This data is indicative of transverse cracking in the outer $90^{\circ}$ ply, where there is increased displacement across a crack, displaying as increased strain in the longitudinal strain data. The load carrying capacity and therefore the stress at the crack has reduced, hence the reduction in the thermoelastic response. It should be noted that some of the decreased thermoelastic response regions do not coincide with the increased strain, such as the region highlighted in Figure 9. This is because of the timing of the data collection, where the TSA is carried out over 8 cycles. Any stress redistribution resulting from damage occurring during these cycles will be integrated across the period of data collection. In contrast, the DIC data is generated from a single 'snap shot' at practically the same time as the TSA data collection period. Figure 10 shows the longitudinal strain and thermoelastic response after 1000 loading cycles. Here the density of the horizontal bands of high strain has increased due to more transverse cracking. Interestingly, the thermoelastic response has reduced indicating that most of the surface ply can no longer carry any stress, which is transferred into the underlying $0^{\circ}$ plies which take the majority of the applied load.

Figure 11 shows the shear strain data between 5000 and 9000 cycles where a feature appears in the bottom right of the image and grows as the cycles progress. It is considered that the feature is caused by a longitudinal split in the subsurface $0^{\circ}$ plies generated the shear strain in the surface plies. The pattern in the longitudinal strain and thermoelastic response remained largely unchanged during this part of the test, because the split material was still carrying the load, as both the split material and the coupon remained attached in the grips of the test machine. 
G.P.Battams and J.M. Dulieu-Barton, "Data-Rich Characterisation of Damage Propagation in Composite Materials", Composites Part A, 2016, doi:10.1016/j.compositesa.2016.08.007

After 14500 cycles a further feature appeared at the top left side of shear strain image shown Figure 12, indicating another longitudinal split in the $0^{\circ}$ layer. At this stage in the test there was an interesting change in the longitudinal strain over a large area of the left specimen edge, not apparent at the appearance of the previous longitudinal split at the right specimen edge. This is considered to be a region of edge delamination. This was confirmed upon inspection of the next data set at 19500 cycles, shown in Figure 13 by the change in the TSA data over the region highlighted by the $\Delta\left(\Delta T / T_{0}\right)$ data set caused by the large change in phase which indicates that the surface ply is detached over this region. It is important to note that this is not evident in the $\Delta T / T_{0}$ data but is highlighted in the phase data. It is considered that the change in phase is as a result of heating caused by the rubbing of the subsurface ply against the delaminated surface ply. Further confirmation of the delamination is provided by inspection of the DIC out of plane displacement data, as shown in Figure 14. The area of delamination can be seen to move towards the camera whilst the rest of the specimen remains in nominally the same position. An important feature in Figure 13 is that the bands in the $\Delta T / T_{0}$ data attributed to horizontal cracking correspond to horizontal bands in the phase data providing further confirmation that the banding in the $\Delta T / T_{0}$ data can be attributed to irreversible heating occurring due to energy release in the cracking process. Minimal change in either the DIC or TSA data was found to occur between 20000 and 240000 cycles, at which the fatigue test was stopped. The final data set is presented in Figure 15.

At the end of the test the specimens were removed from the test machine and X-ray CT scanned using a custom $225 \mathrm{kV}$ Nikon/Metris HMX ST machine operating at $60 \mathrm{kV}$. 3143 radiographs of 2000 x 2000 pixels were taken at $0.115^{\circ}$ angular steps. After 3D reconstruction, voxel sizes of $10.1 \mu \mathrm{m}$ were obtained. Three vertical and three horizontal CT cross sections were extracted. The vertical cross sections are shown in Figure 16 and were taken at $3.0 \mathrm{~mm}$ and $2.9 \mathrm{~mm}$ from the right and left edges of the specimen respectively and along the specimen centreline. The horizontal cross sections are shown in Figure 17 and were taken from the left side of the specimen to the specimen centre line at the top middle and bottom of the DIC imaging area. The final longitudinal strain data is plotted in Figure 16 at the initial reference subset locations, i.e. the strain map does not deform with applied loading, so allowing the data to be representative of the unloaded specimen in the CT scan; any residual deformation due to damage will still exist in the specimen. The CT images in Figure 16 show that transverse cracking occurs through the entire surface ply and the superficial paint layer at locations that correspond with increased longitudinal strain. A large area of delamination can be seen in the 
G.P.Battams and J.M. Dulieu-Barton, "Data-Rich Characterisation of Damage Propagation in Composite Materials", Composites Part A, 2016, doi:10.1016/j.compositesa.2016.08.007

CT images given in Figure 17 between the outer $90^{\circ}$ and inner $0^{\circ}$ layers as highlighted in the image. The edge delamination penetrates approximately $5.2 \mathrm{~mm}$ into the specimen at the top and middle locations, whilst at the bottom location, the delamination penetrated approximately $8.3 \mathrm{~mm}$. This matches well with the extent of the out of phase regions present in Figure 15, which are larger at the bottom of the image.

Longitudinal splitting in the central $0^{\circ}$ layers is evident in Figure 17 at the left specimen edge. The split extends the full length of the CT scan area at approximately $1.3 \mathrm{~mm}$ from the left specimen edge, matching well with the region of increased shear strain shown in Figures 12, 13 and 15, which starts at $1.4 \mathrm{~mm}$ from the left specimen free edge. As the longitudinal split is no longer attached to the central part of the specimen, strain transfer cannot occur and a shearing displacement occurs. Since the longitudinal split is likely to remain partly adhered to the outer $90^{\circ}$ ply, the relative movement manifests itself as a shear strain in the surface ply. The CT scan area did not extend fully to the right specimen edge and as a result, the damage behaviour at this location could not be verified.

\section{Damaged specimens}

A CFRP specimen which was damaged using the interrupted loading rig was subsequently loaded under the conditions stated in Table 4 and imaged using the methodology previously described. The damage identified during intermediate strain rate loading could not be resolved in the initial stages of fatigue loading. This is because under the applied loading conditions a rapid onset of further transverse cracking occurred in the initial few cycles. Longitudinal strain and $\Delta T / T_{0}$ data from the first data set is shown in Figure 18, which manifested in a practically identical manner to that of the undamaged specimen.

As shown in Figure 19, the first evidence of longitudinal splitting occurred in the shear strain data at 3000 cycles, close to the right specimen edge, earlier than the undamaged specimen. In the next 1000 cycles this was found to progress in a similar manner to the undamaged specimen into a longitudinal split extending the full height of the field of view. As a limited number of samples were tested, further work would be required to prove a causal link between intermediate strain rate loading and an increased tendency for longitudinal splitting in this material.

The longitudinal strain and $\Delta T / T_{0}$ data was then found to progress in a very similar manner to the undamaged specimen. However, the shear strain and phase data was found to be quite different, indicating a different behaviour. Shear strain and TSA phase data for the final data 
G.P.Battams and J.M. Dulieu-Barton, "Data-Rich Characterisation of Damage Propagation in Composite Materials", Composites Part A, 2016, doi:10.1016/j.compositesa.2016.08.007

set are shown in Figure 20. Whilst longitudinal splitting is clearly indicated at the right edge, no evidence of longitudinal splitting could be noted in any of the data types at the left specimen edge. X-Ray CT analysis, as shown in Figure 21, reveals that longitudinal splits did occur in the central $0^{\circ}$ plies at both specimen edges. The difference in shear strain and phase behaviour between the two longitudinal splits can be explained by visual inspection of the specimen. A bundle of $0^{\circ}$ fibres was found to be detached from the top end tab region at the right specimen edge and consequently have no load bearing capacity. The split at the left edge however, remains attached to the bulk of the specimen and hence remains load bearing throughout the test, resulting in low relative displacement and hence no noticeable change in the shear strain data.

\section{Conclusions}

A new methodology that combines TSA and DIC for the study of damage in FRP materials during fatigue loading without the requirement to interrupt the test has been defined. It has been shown that features in the data generated from both the TSA and the DIC can be used to identify the evolution of different damage types, including transverse cracking, longitudinal splitting and delaminations, which were verified using X-ray CT inspections.

The work represents the first step in using a combined DIC/TSA technique for damage characterisation. The specimens used in the study were chosen especially as it was known that surface damage would occur early in the fatigue life on the surface. However it has also been shown that sub surface features also have an effect on the surface response and can be identified. The fatigue tests were stopped prior to final failure so fibre breakage in the sub surface UD plies was not identified. An area for future work is clearly to examine more realistic and representative stacking sequences and laminate thickness. The potential of the technique for use in actual component testing has been demonstrated. It offers a new tool that can be applied during fatigue testing alongside conventional measurements such as strain gauges, ahead of post-mortem evaluations. Clearly the next stage in the work will be to devise a way of making quantitative evaluations of the damage based on the strain evaluated from the DIC and the stress metric obtained from the TSA. Another area for further work would be to use the approach to define failure in fatigue testing of composite materials. Both of these topics are objects of current investigations at the University of Southampton.

\section{Acknowledgements}


G.P.Battams and J.M. Dulieu-Barton, "Data-Rich Characterisation of Damage Propagation in Composite Materials", Composites Part A, 2016, doi:10.1016/j.compositesa.2016.08.007

The research was funded by the Engineering and Physical Sciences Research Council (EPSRC) Grant Number EP/G042403/1 and the Defence and Science Technology Laboratories (DSTL). The authors thank the continuing support of the academic and industrial collaborators who formed the industrial advisory board during the project as follows: Aalborg University, Airbus, Arts et Métiers ParisTech, FLIR ATS, GE Aviation, LaVision, Lloyd’s Register. The high speed white light cameras were borrowed from the Engineering Instrument Pool (EIP).

\section{References}

[1] M. Daniel and O. Ishai, Engineering Mechanics of Composite Materials. New York, (1994).

[2] A. M. S. Hamouda and M. S. J. Hashmi, "Testing of composite materials at high rates of strain: advances and challenges," Journal of Materials Processing Technology, vol. 77, pp. 327-336, (1998).

[3] G.P. Battams, "The use of optical techniques to assess the damage tolerance of composite materials”, PhD Thesis, University of Southampton, 2014. Available online http://eprints.soton.ac.uk/363784/1.hasCoversheetVersion/Gary_Battams_Final\%20th esis.pdf

[4] M. A. Sutton, J.-J. Orteu, and H. W. Schreier, Image Correlation for Shape, Motion and Deformation Measurements, Springer US, 2009.

[5] B. Pan, K. Qian, H. Xie, and A. Asundi, "Two-dimensional digital image correlation for in-plane displacement and strain measurement: a review," Measurement Science and Technology, 20, 2009.

[6] B. Pan, "Recent Progress in Digital Image Correlation," Experimental Mechanics, 51, pp. 1223-1235, 2011.

[7] J.M. Dulieu-Barton “Thermoelastic Stress Analysis”, in Optical Methods for Solid Mechanics, Wiley-VCH, 2012, pp 345-366

[8] T. R. Emery and J. M. Dulieu-Barton, "Thermoelastic Stress Analysis of damage mechanisms in composite materials," Composites Part A: Applied Science and Manufacturing, 41, pp. 1729-1742, 2010.

[9] R.K. Frühmann, J.M. Dulieu-Barton and S. Quinn, “Assessment of fatigue damage evolution in woven composite materials using infra-red techniques” Composites Science and Technology, 70, pp 937-946, 2010.

[10] F. Meraghni, H. Nouri, N. Bourgeois, C. Czarnota, and P. Lory, "Parameters identification of fatigue damage model for short glass fiber reinforced polyamide (PA6-GF30) using digital image correlation," Procedia Engineering, vol. 10, pp. 2110-2116, (2011).

[11] S. Giancane, F. W. Panella, R. Nobile, and V. Dattoma, "Fatigue damage evolution of fiber reinforced composites with digital image correlation analysis," Procedia Engineering, vol. 2, pp. 1307-1315, (2010).

[12] A. Chrysochoos, B. Berthel, F. Latourte, A. Galtier, S. Pagano, and B. Wattrisse, "Local energy analysis of high-cycle fatigue using digital image correlation and 
G.P.Battams and J.M. Dulieu-Barton, "Data-Rich Characterisation of Damage Propagation in Composite Materials", Composites Part A, 2016, doi:10.1016/j.compositesa.2016.08.007

infrared thermography." The Journal of Strain Analysis for Engineering Design 43.6 (2008): 411-422.

[13] A.Chrysochoos, V. Huon, F. Jourdon, J. Muracciole, R. Peyroux and B. Wattrisse "Use of Full-Field Digital Image Correlation and Infrared Thermography

Measurements for the Thermomechanical Analysis of Material Behaviour." Strain vol. 46, 2010, 117-130.

[14] L. Bodelot, E. Charkaluk, L. Sabatier and P Dufrénoy. "Experimental study of heterogeneities in strain and temperature fields at the microstructural level of polycrystalline metals through fully-coupled full-field measurements by Digital Image Correlation and Infrared Thermography." Mechanics of Materials vol .43, 2011, 654670.

[15] W. Wang, R.K. Fruehmann and J.M. Dulieu-Barton, “Application of digital image correlation to reduce the effect of complex motions in thermoelastic stress analysis", Strain, in press 2015. doi: 10.1111/str.12151.

[16] G. Crammond, S.W. Boyd and J.M.Dulieu-Barton, "A point-wise approach to the analysis of complex composite structures using digital image correlation and thermoelastic stress analysis”, Strain, 51, 2015, 311-323. DOI: 10.1111/str.12142

[17] M. L. Silva and G. Ravichandran, "Combined thermoelastic stress analysis and digital image correlation with a single infrared camera," The Journal of Strain Analysis for Engineering Design, 2011 vol. 46, pp. 783-793.

[18] C. Goidescu, H. Welemane, C. Garnier, M. Fazzini, R. Brault, E. Péronnet, et al., "Damage investigation in CFRP composites using full-field measurement techniques: Combination of digital image stereo-correlation, infrared thermography and X-ray tomography," Composites Part B: Engineering, vol. 48, pp. 95-105, (2013).

[19] A.K. Wong, A non-adiabatic thermoelastic theory for composite laminates. $J$ Phys Chem Solid 1991, 52(3): 483-494.

[20] R.K. Fruehmann, J.M Dulieu-Barton, S. Quinn and J.P. Tyler, “The use of a lock-in amplifier to apply digital image correlation to cyclically loaded components”, Optics and Lasers in Engineering, 68, 2015, 149-159.

[21] K. Hoiseth and J. Qu, "Cracking paths at the ply interface in a cross-ply laminate," Composites Part B: Engineering, vol. 34, pp. 437-445, (2003).

[22] J. M. Berthelot, A. E. Mahi, and J. F. Le Corre, "Development of transverse cracking in cross-ply laminates during fatigue tests," Composites Science and Technology, vol. 61, pp. 1711-1721, (2001).

[23] S. Ogihara and N. Takeda, "Interaction between transverse cracks and delamination during damage progress in CFRP cross-ply laminates," Composites Science and Technology, vol. 54, pp. 395-404, (1995).

[24] M.L. Longana, J.M. Dulieu-Barton, F. Pierron and S. Syngellakis, "Identification of constitutive properties of composite materials under high strain rate loading using optical strain measurement techniques" 15th European Conference on Composite Materials, 2012, Venice, Italy, 8 pages on CD.

[25] Crammond, G., Boyd, S.W. and Dulieu-Barton, J.M., "Speckle pattern quality assessment for digital image correlation”, Optics and Lasers in Engineering, 2013, 51, 1368-1378. DOI: http://dx.doi.org/10.1016/j.optlaseng.2013.03.014 
G.P.Battams and J.M. Dulieu-Barton, "Data-Rich Characterisation of Damage Propagation in

Composite Materials", Composites Part A, 2016, doi:10.1016/j.compositesa.2016.08.007

[26] R.K. Fruehmann, D.A. Crump and J.M. Dulieu-Barton, "Characterization of an infrared detector for high frame rate thermography”, Meas. Sci. Technol. 2013, 24,105403 (12pp). DOI 10.1088/0957-0233/24/10/105403

[27] G. P Battams, D. A. Crump, S. W. Boyd, J. M. Dulieu-Barton, "Systematic Errors in the Use of High Speed Cameras for Digital Image Correlation”, High Speed Imaging for Dynamic Testing of Materials and Structures, London, UK (2013).

[28] H. W. Schreier, J. R. Braasch, and M. A. Sutton, "Systematic errors in digital image correlation caused by intensity interpolation," Optical Engineering, vol. 39, pp. 29152921, (2000).

[29] P. Lava, S. Cooreman, S. Coppieters, M. De Strycker, and D. Debruyne, “Assessment of measuring errors in DIC using deformation fields generated by plastic FEA," Optics and Lasers in Engineering, vol. 47, pp. 747-753, (2009) 
G.P.Battams and J.M. Dulieu-Barton, "Data-Rich Characterisation of Damage Propagation in Composite Materials", Composites Part A, 2016, doi:10.1016/j.compositesa.2016.08.007

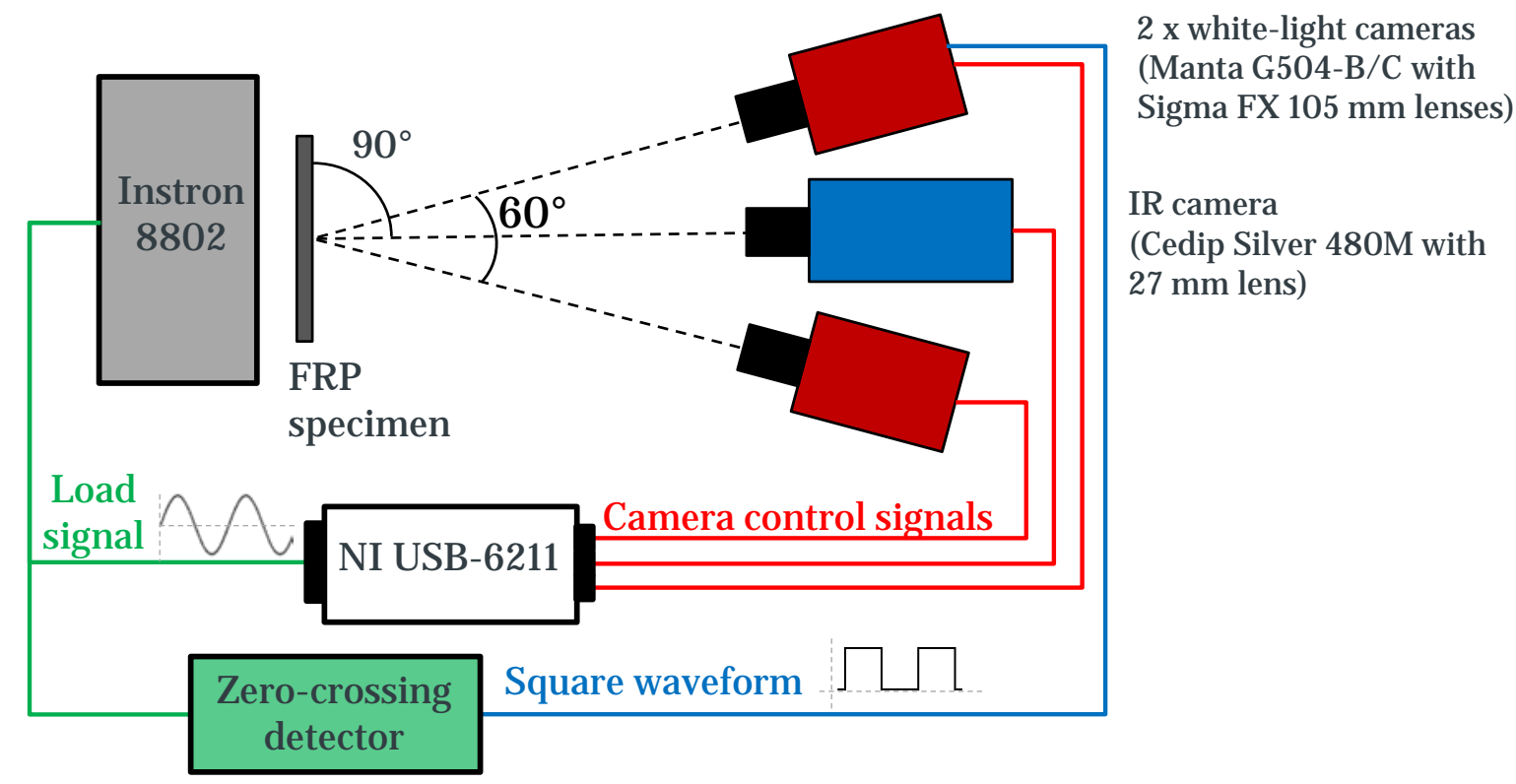

Figure 1: Equipment overview

IR images taken White light images taken

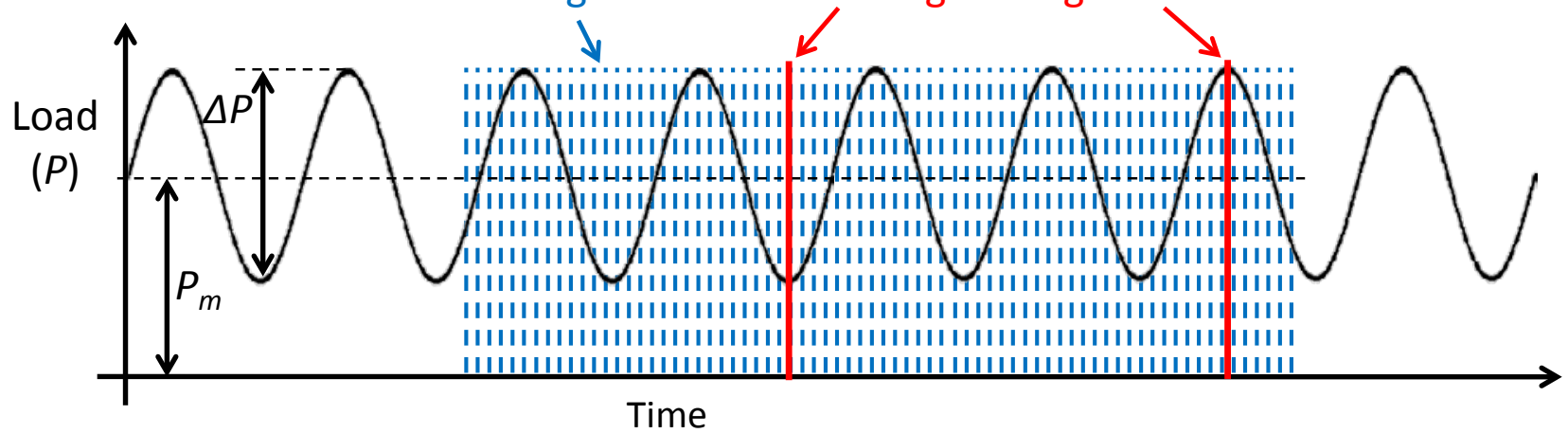

Figure 2: Schematic of image capture timing method 
G.P.Battams and J.M. Dulieu-Barton, "Data-Rich Characterisation of Damage Propagation in Composite Materials", Composites Part A, 2016, doi:10.1016/j.compositesa.2016.08.007

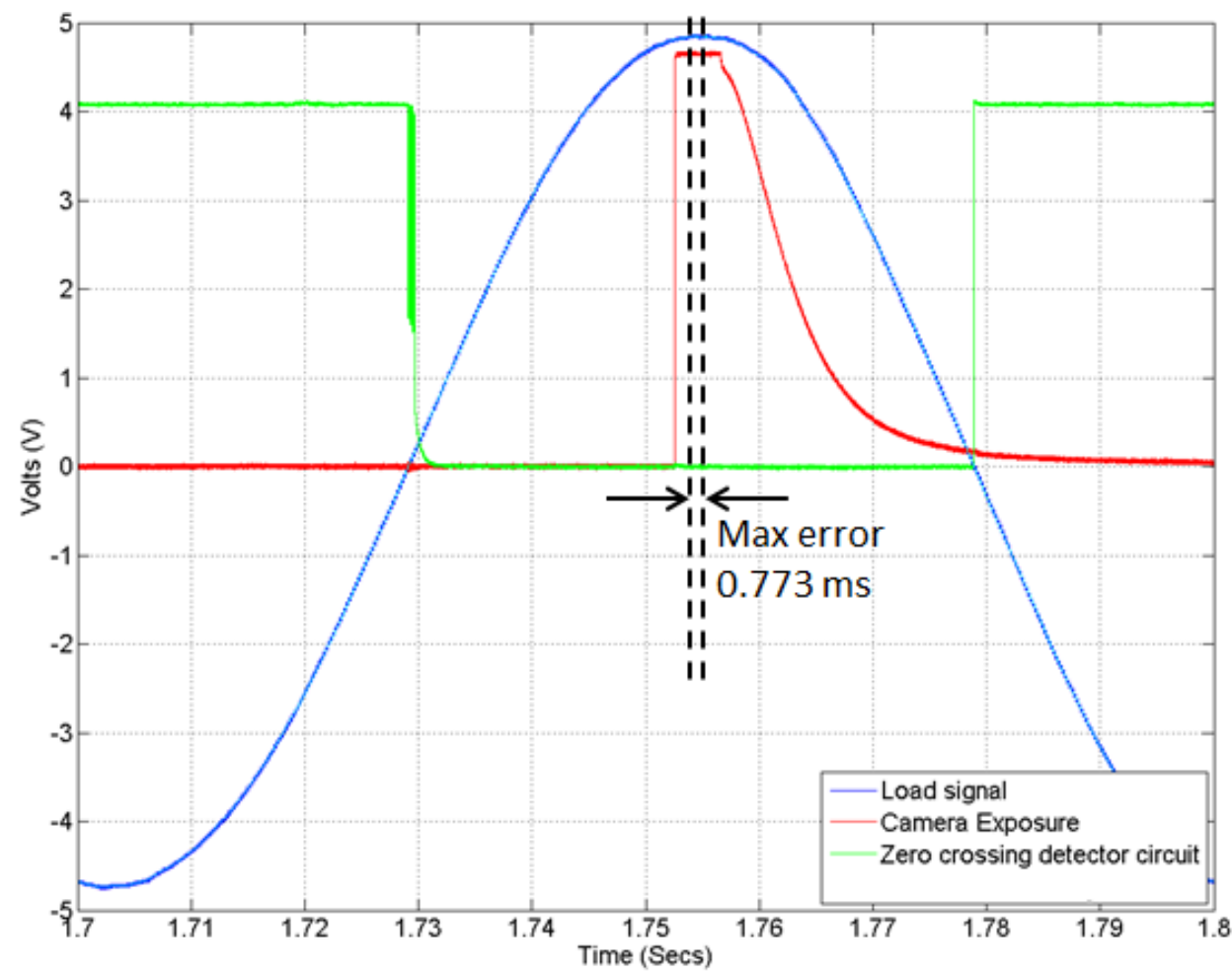

Figure 3: Image from oscilloscope showing white-light image timing error

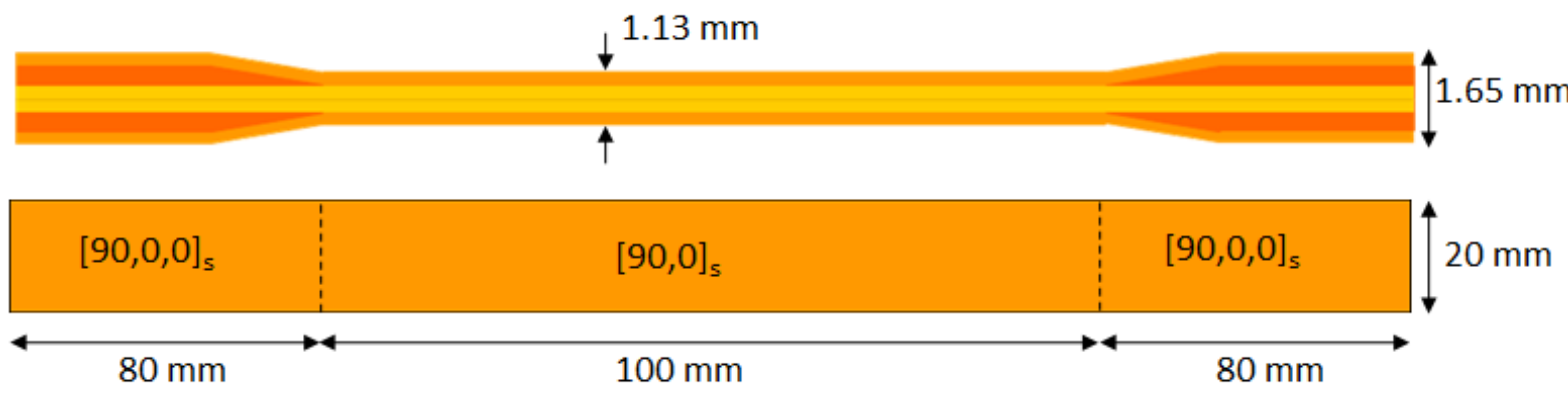

Figure 4: CFRP specimen configuration and geometry 

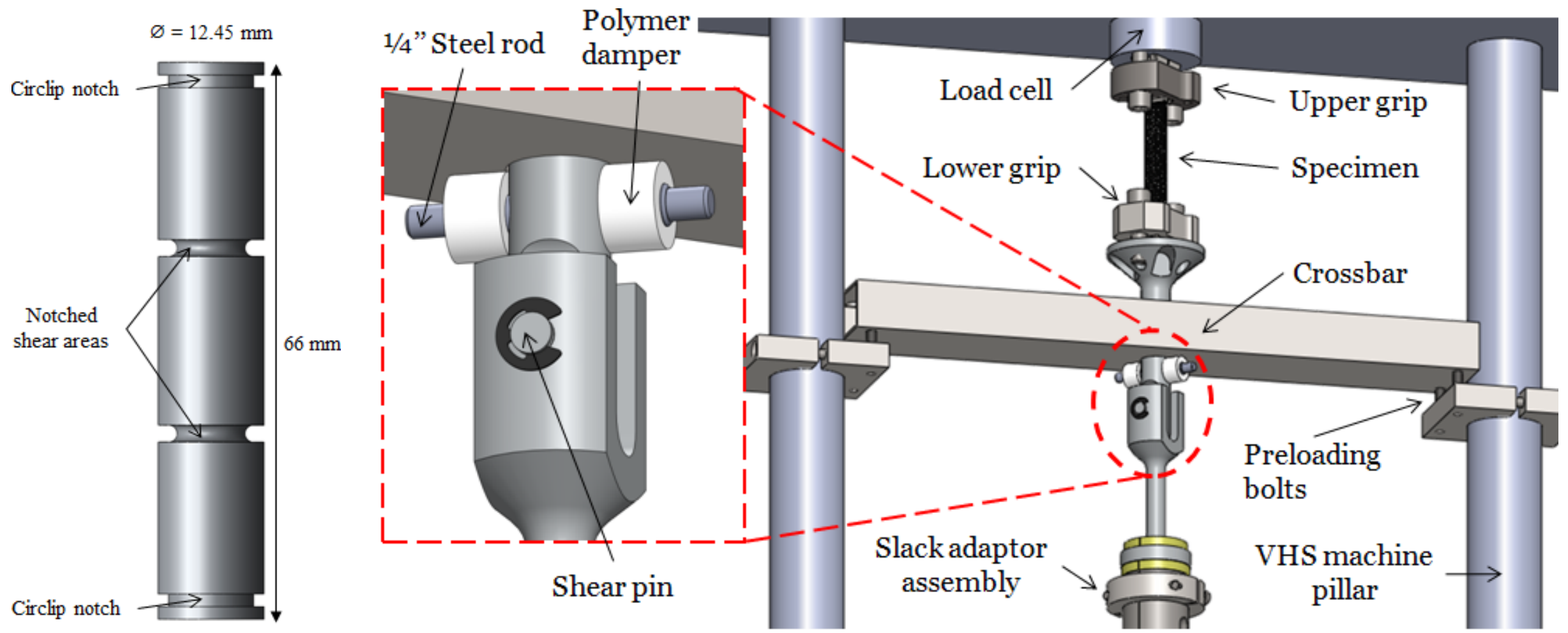

Figure 5: Interrupted loading rig 

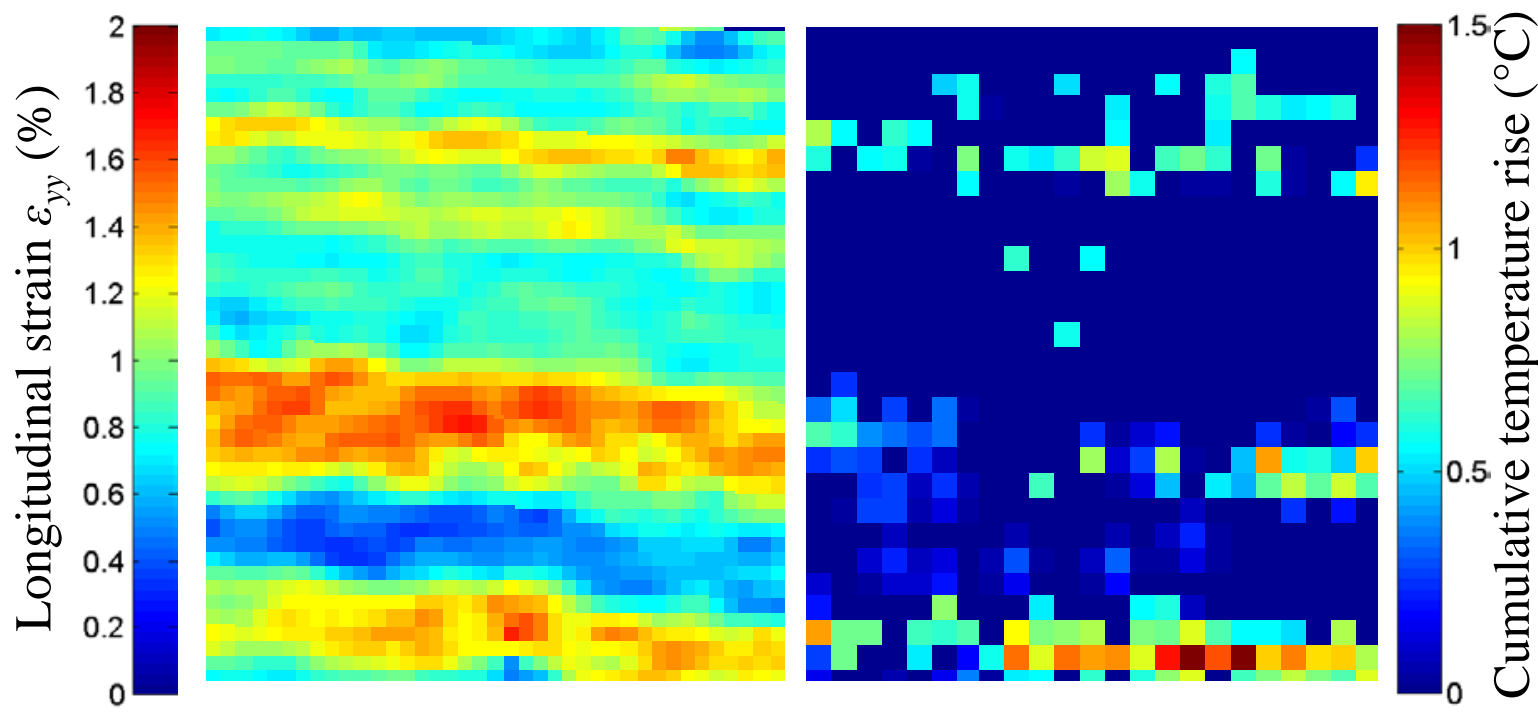

Figure 6: DIC Longitudinal strain data and cumulative temperature rise data (with a $0.5^{\circ} \mathrm{C}$ threshold applied) for a CFRP specimen loaded at an intermediate strain rate (11.1 s $\left.\mathrm{s}^{-1}\right)$

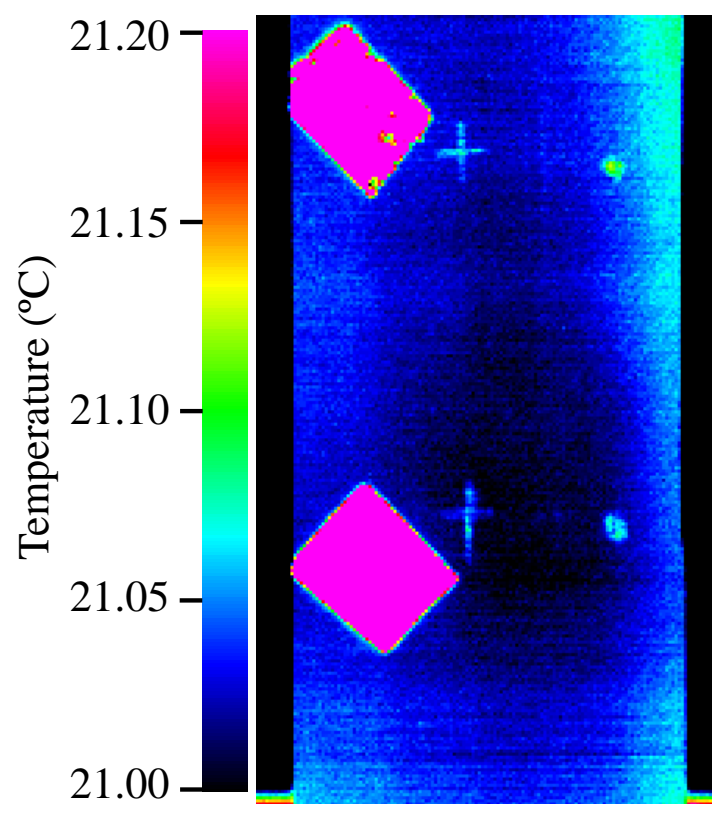

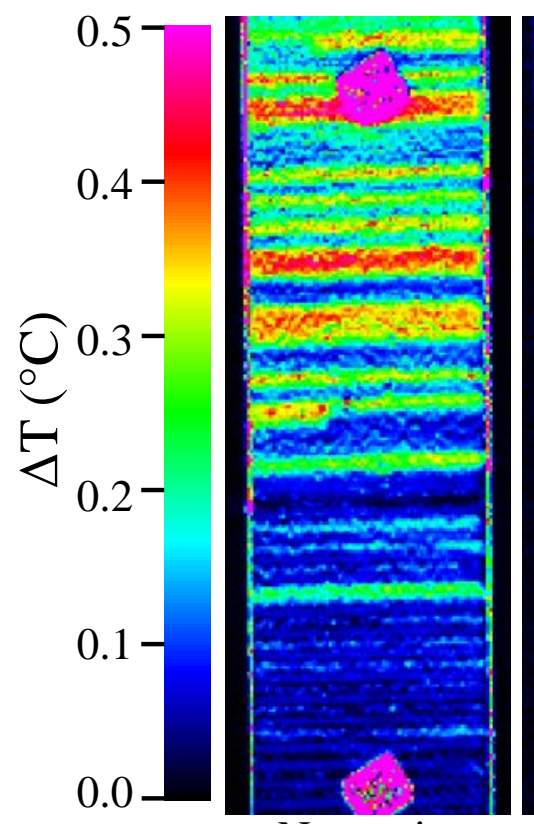

No motion

compensation

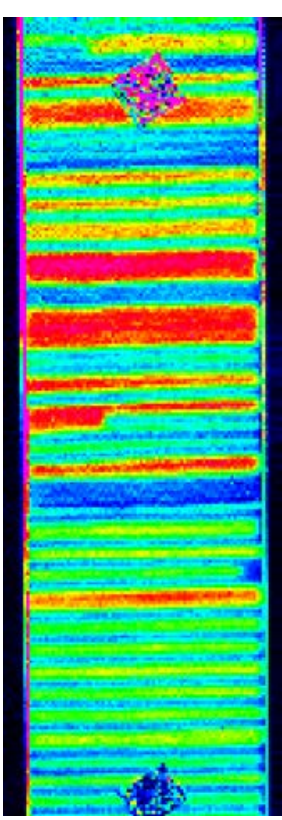

Motion

compensated

Figure 7: Left: IR image of motion compensation reference mark trial, showing aluminium foil (left), pencil lead (centre left), ballpoint pen (centre right) and Tippex (right) markers. Right: Effect of motion compensation on thermoelastic data clarity. 
G.P.Battams and J.M. Dulieu-Barton, "Data-Rich Characterisation of Damage Propagation in Composite Materials", Composites Part A, 2016, doi:10.1016/j.compositesa.2016.08.007

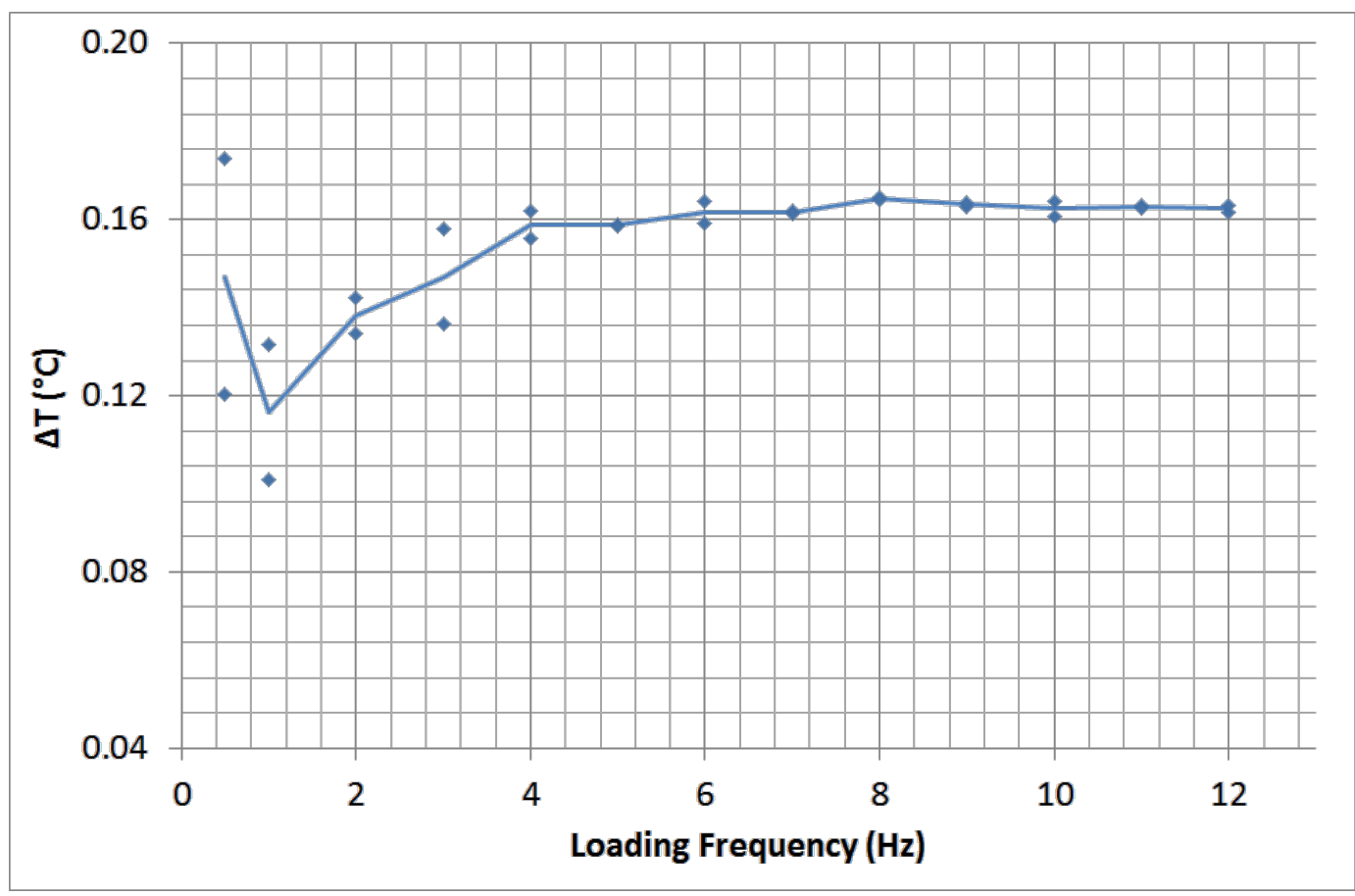

Figure 8: Effect of loading frequency on the thermoelastic response of speckle patterned CFRP
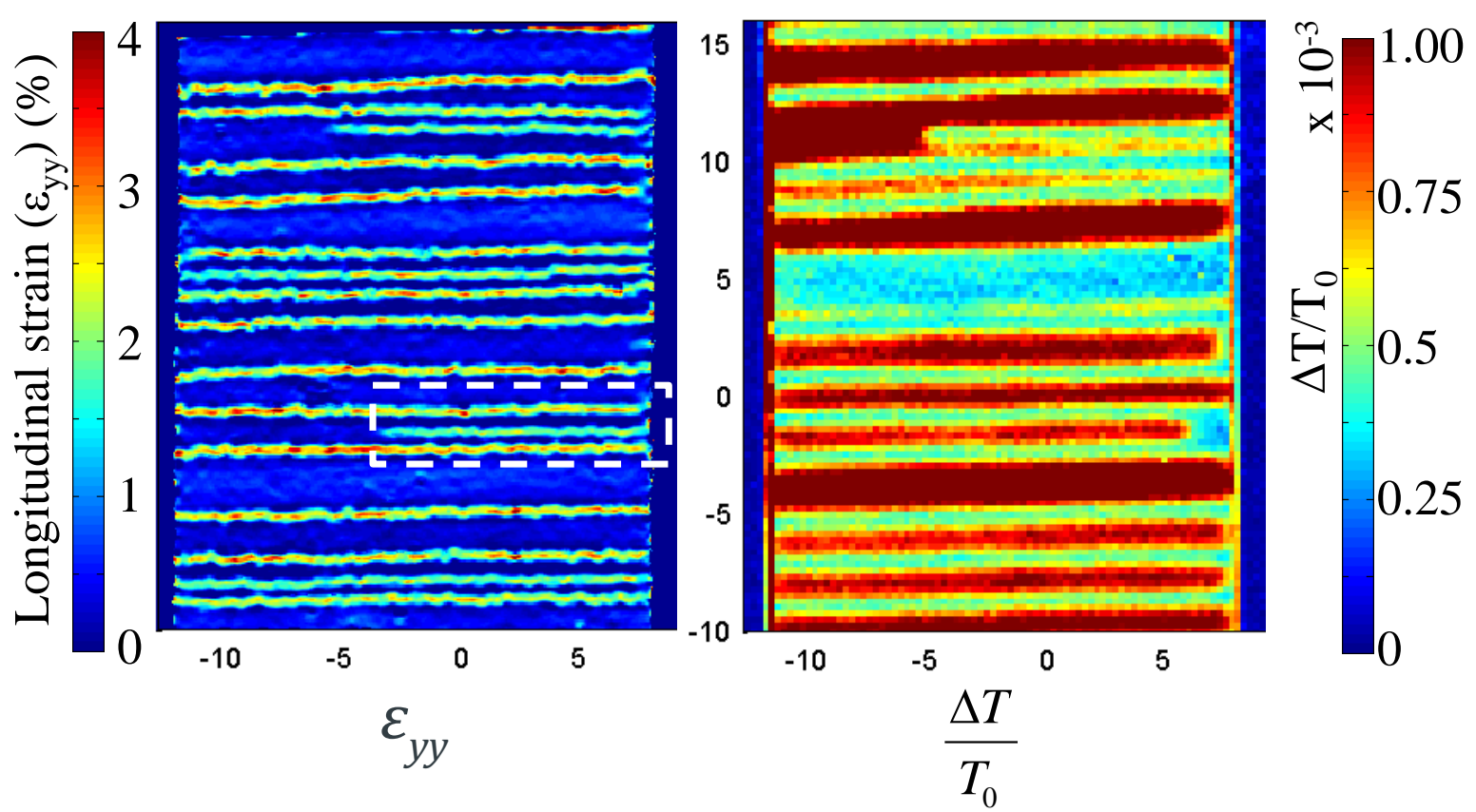

Figure 9: Longitudinal strain $\left(\varepsilon_{y y}\right)$ and normalised thermoelastic response $\left(\Delta T / T_{0}\right)$ at the start of fatigue life of the undamaged crossply CFRP specimen. 
G.P.Battams and J.M. Dulieu-Barton, "Data-Rich Characterisation of Damage Propagation in Composite Materials", Composites Part A, 2016, doi:10.1016/j.compositesa.2016.08.007
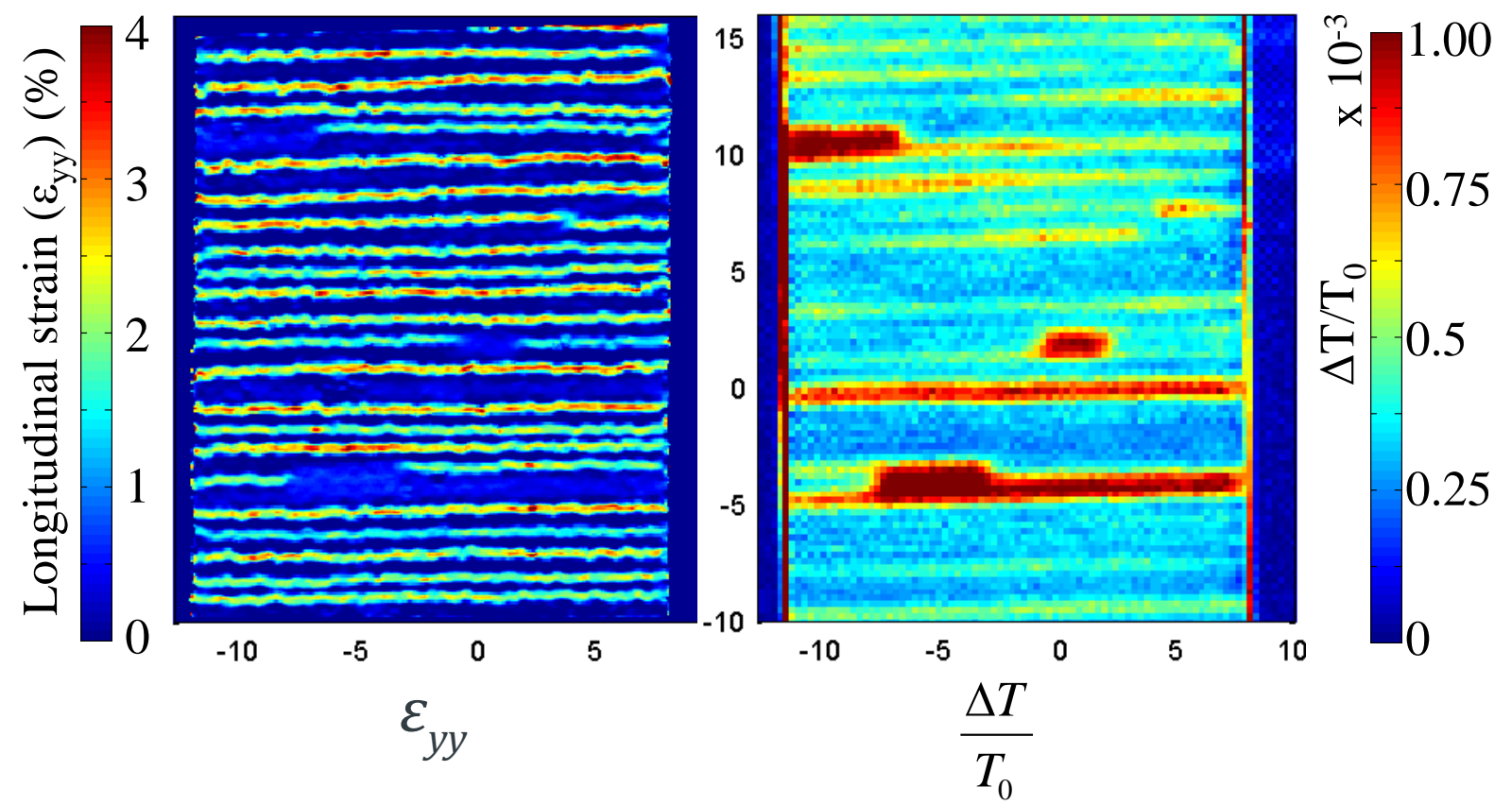

Figure 10: Longitudinal strain ( $\left.\varepsilon_{y y}\right)$ and normalised thermoelastic response $\left(\Delta T / T_{0}\right)$ at 1000 loading cycles of the undamaged crossply CFRP specimen.
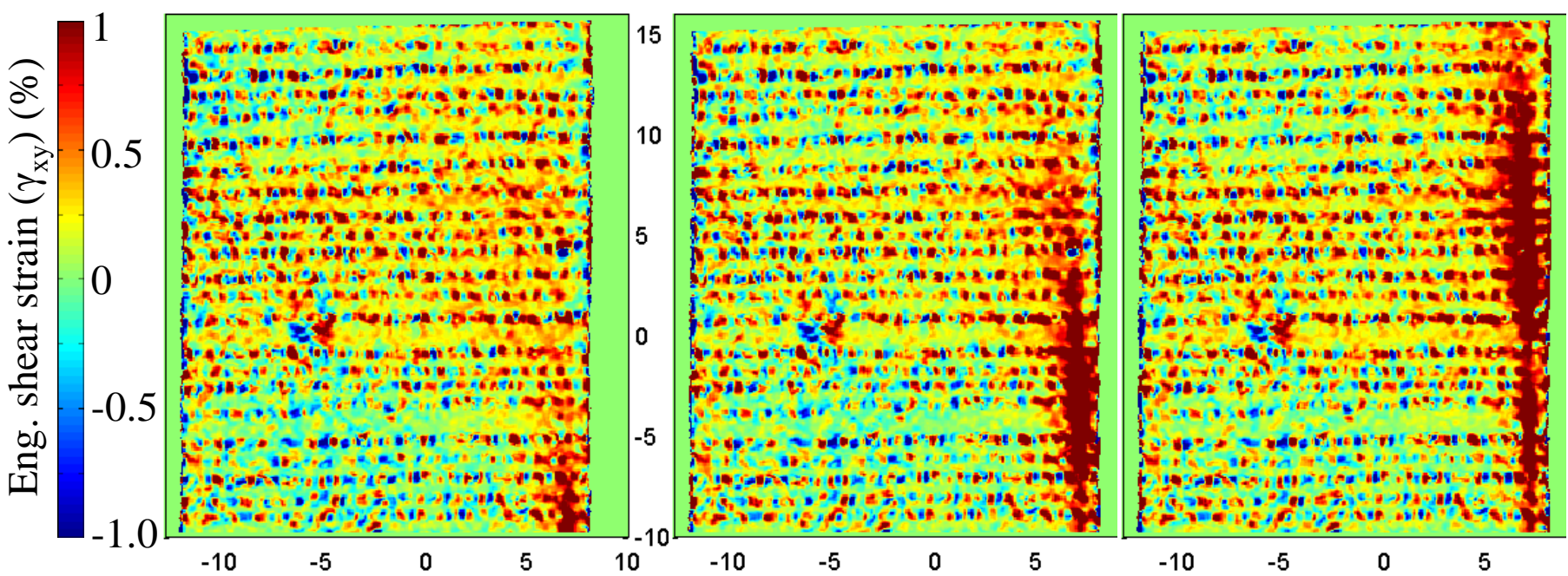

Loading

Cycles:

5000

8000

9000

Figure 11: Development of engineering shear strain $\left(\gamma_{x y}\right)$ in the undamaged crossply CFRP specimen. 
G.P.Battams and J.M. Dulieu-Barton, "Data-Rich Characterisation of Damage Propagation in Composite Materials", Composites Part A, 2016, doi:10.1016/j.compositesa.2016.08.007
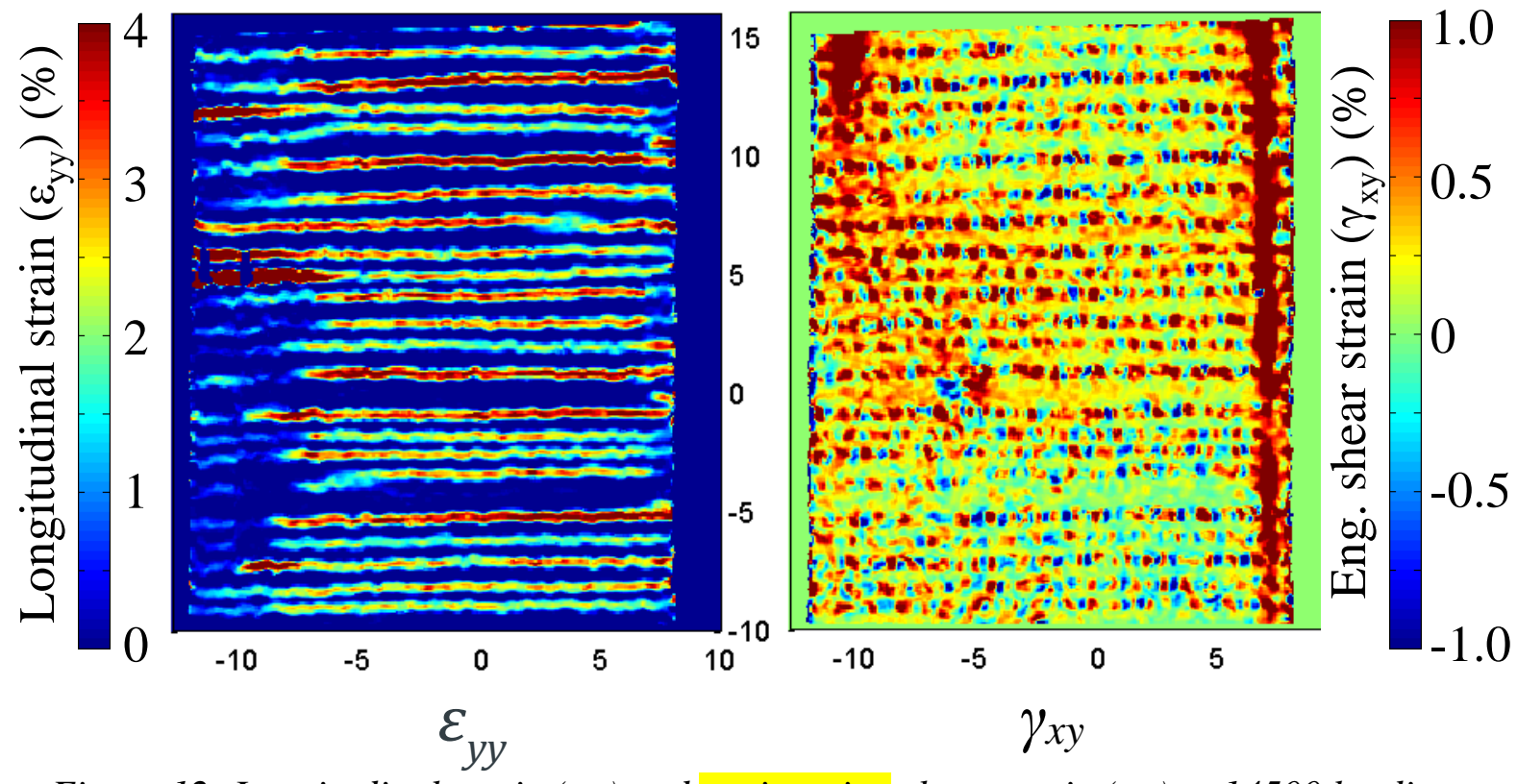

Figure 12: Longitudinal strain ( $\left.\varepsilon_{y y}\right)$ and engineering shear strain $\left(\gamma_{x y}\right)$ at 14500 loading cycles of the undamaged crossply CFRP specimen. 
G.P.Battams and J.M. Dulieu-Barton, "Data-Rich Characterisation of Damage Propagation in Composite Materials", Composites Part A, 2016, doi:10.1016/j.compositesa.2016.08.007
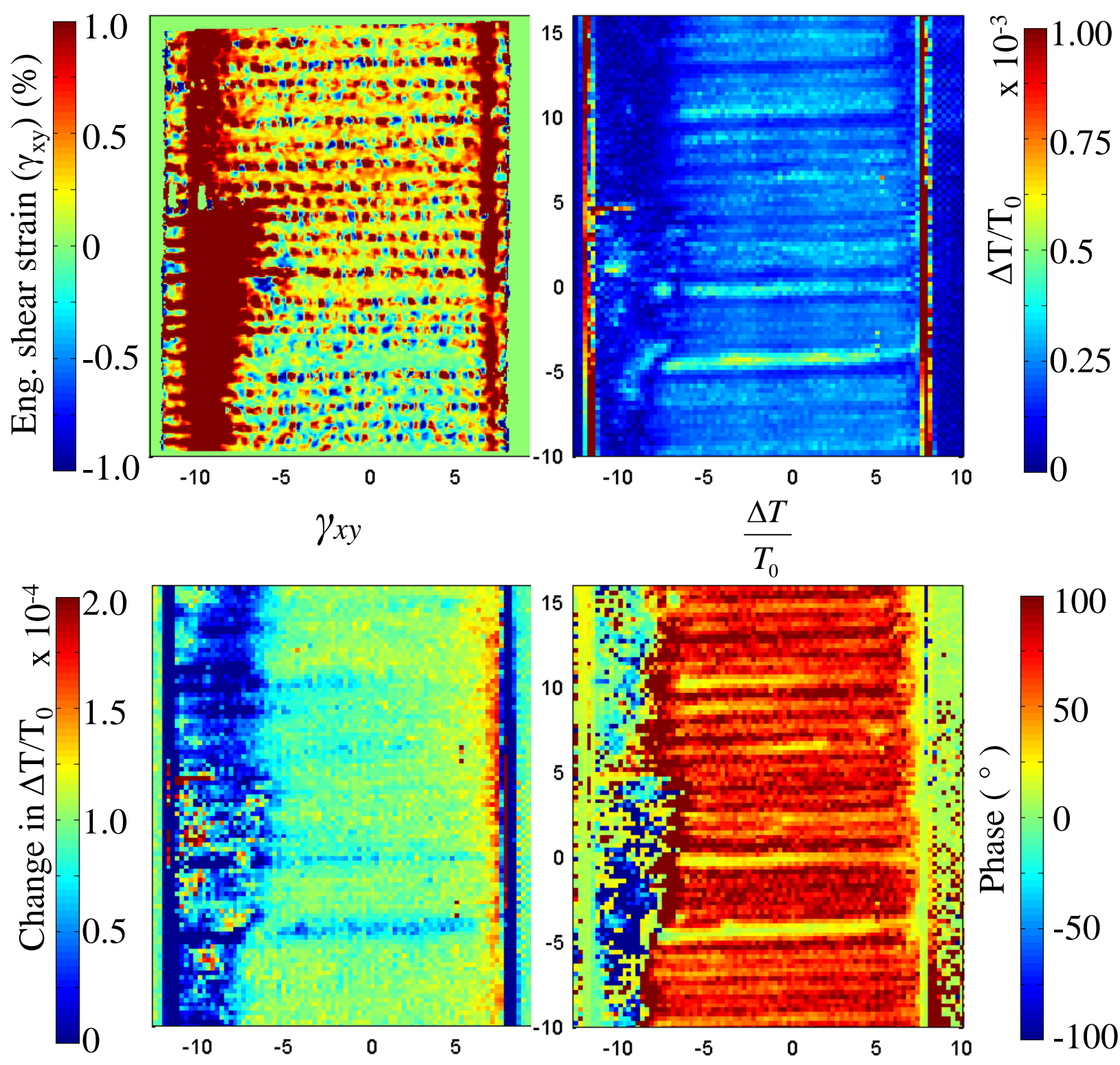

$$
\left(\frac{\Delta T}{T_{0}}\right)_{n}-\left(\frac{\Delta T}{T_{0}}\right)_{n-1}
$$

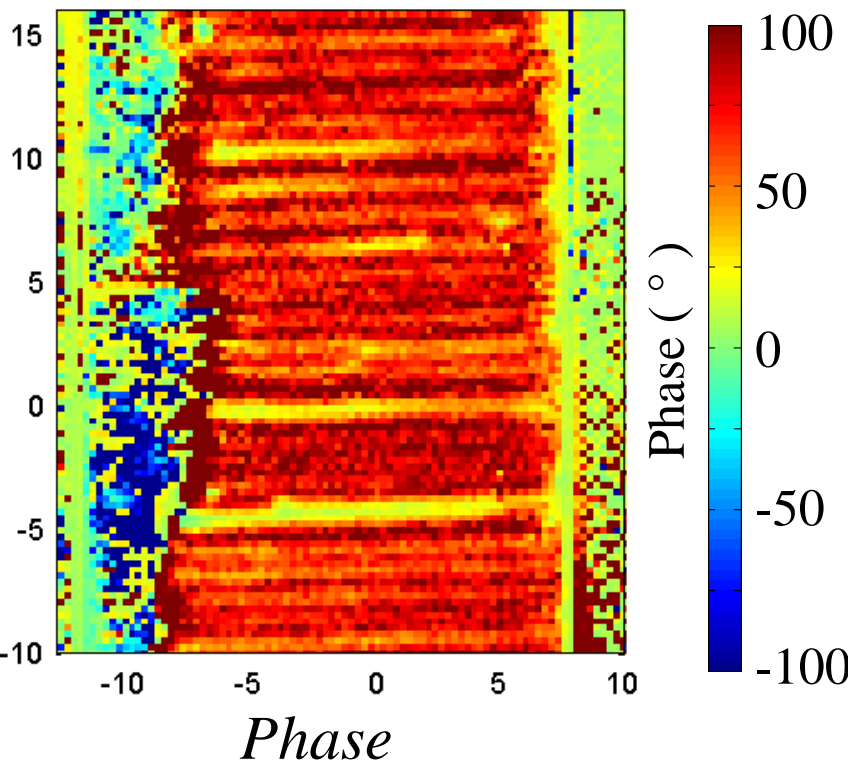

Figure 13: Engineering shear strain $\left(\gamma_{x y}\right)$ and all thermoelastic data types at 19500 loading cycles of the undamaged crossply CFRP specimen. 
G.P.Battams and J.M. Dulieu-Barton, "Data-Rich Characterisation of Damage Propagation in Composite Materials", Composites Part A, 2016, doi:10.1016/j.compositesa.2016.08.007

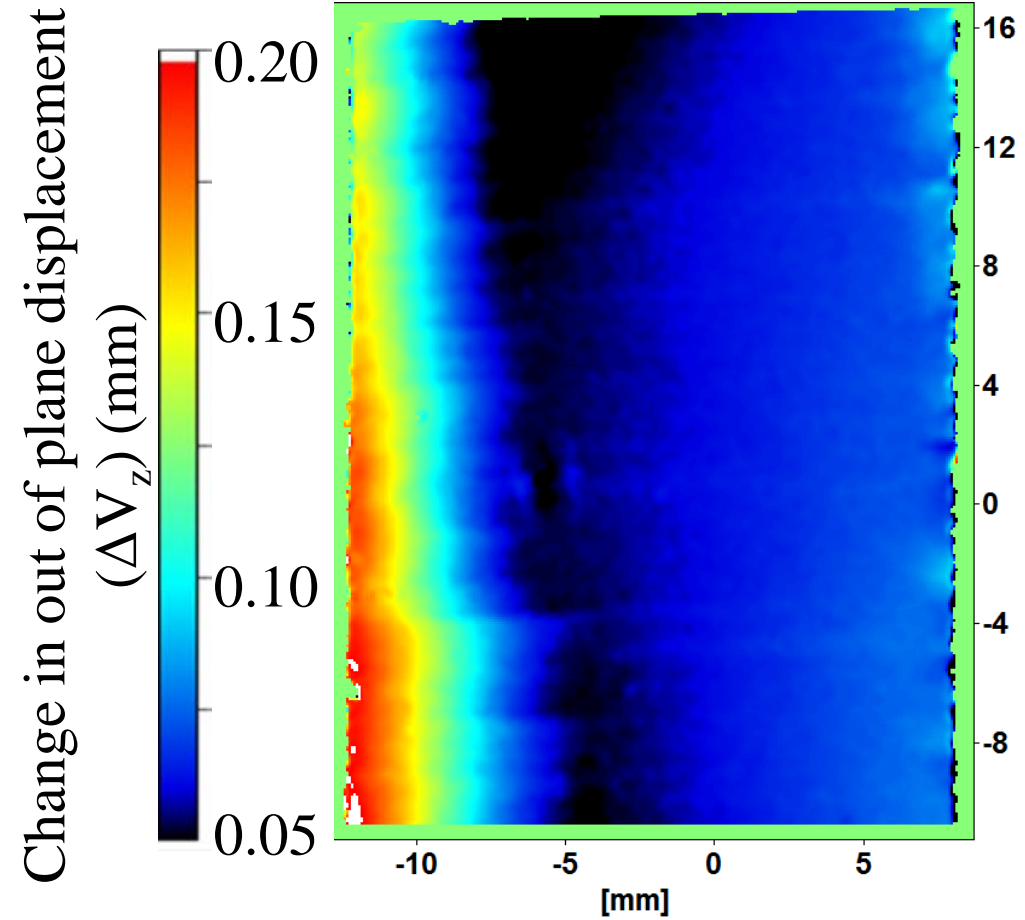

Figure 14: Change in out of plane displacement between 9.5 and 24.5 thousand cycles. 
G.P.Battams and J.M. Dulieu-Barton, "Data-Rich Characterisation of Damage Propagation in Composite Materials", Composites Part A, 2016, doi:10.1016/j.compositesa.2016.08.007
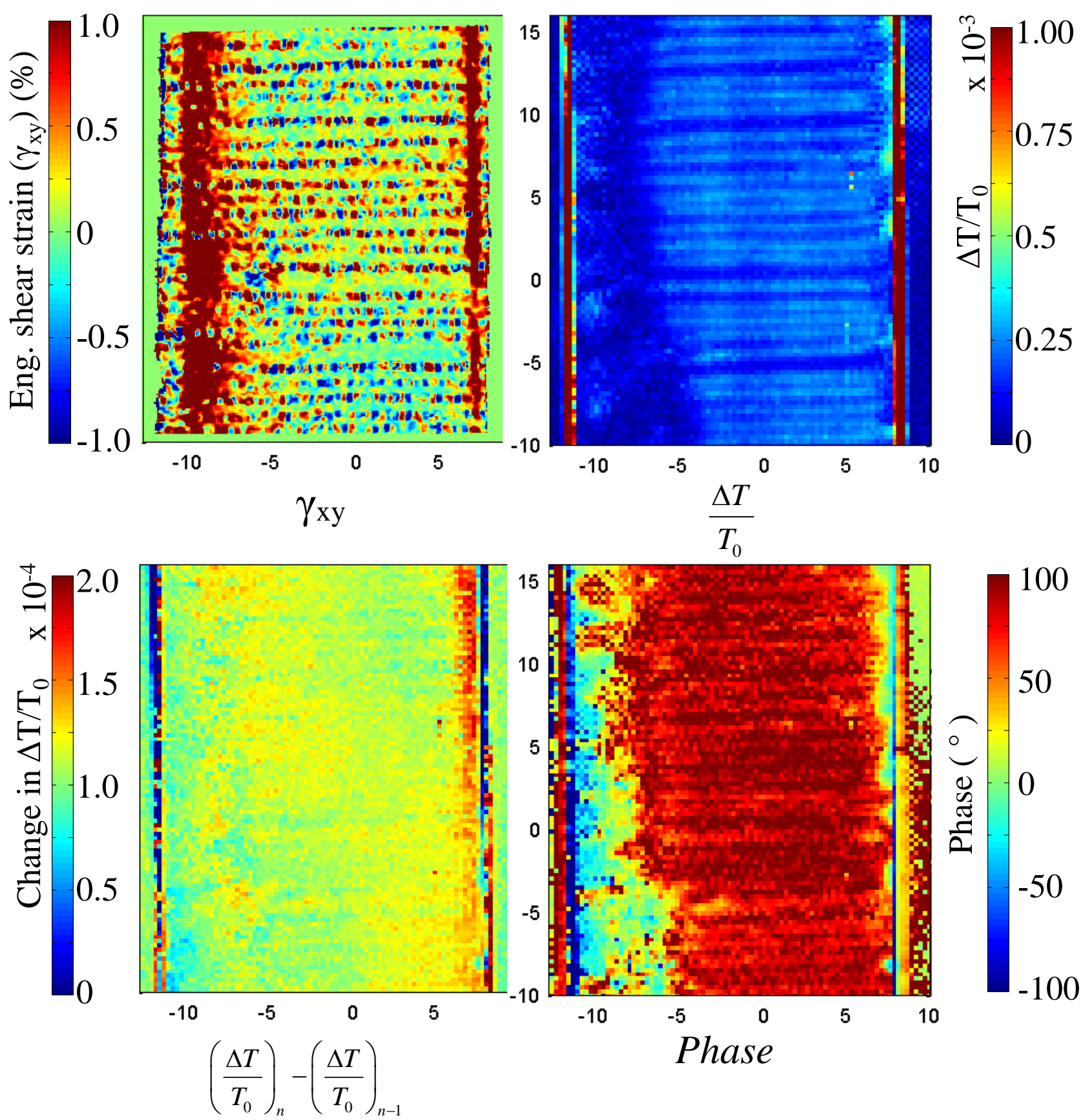

Figure 15: Engineering shear strain $\left(\varepsilon_{y y}\right)$ and all thermoelastic data types at 240000 loading cycles of the undamaged crossply CFRP specimen. 
G.P.Battams and J.M. Dulieu-Barton, "Data-Rich Characterisation of Damage Propagation in Composite Materials", Composites Part A, 2016, doi:10.1016/j.compositesa.2016.08.007
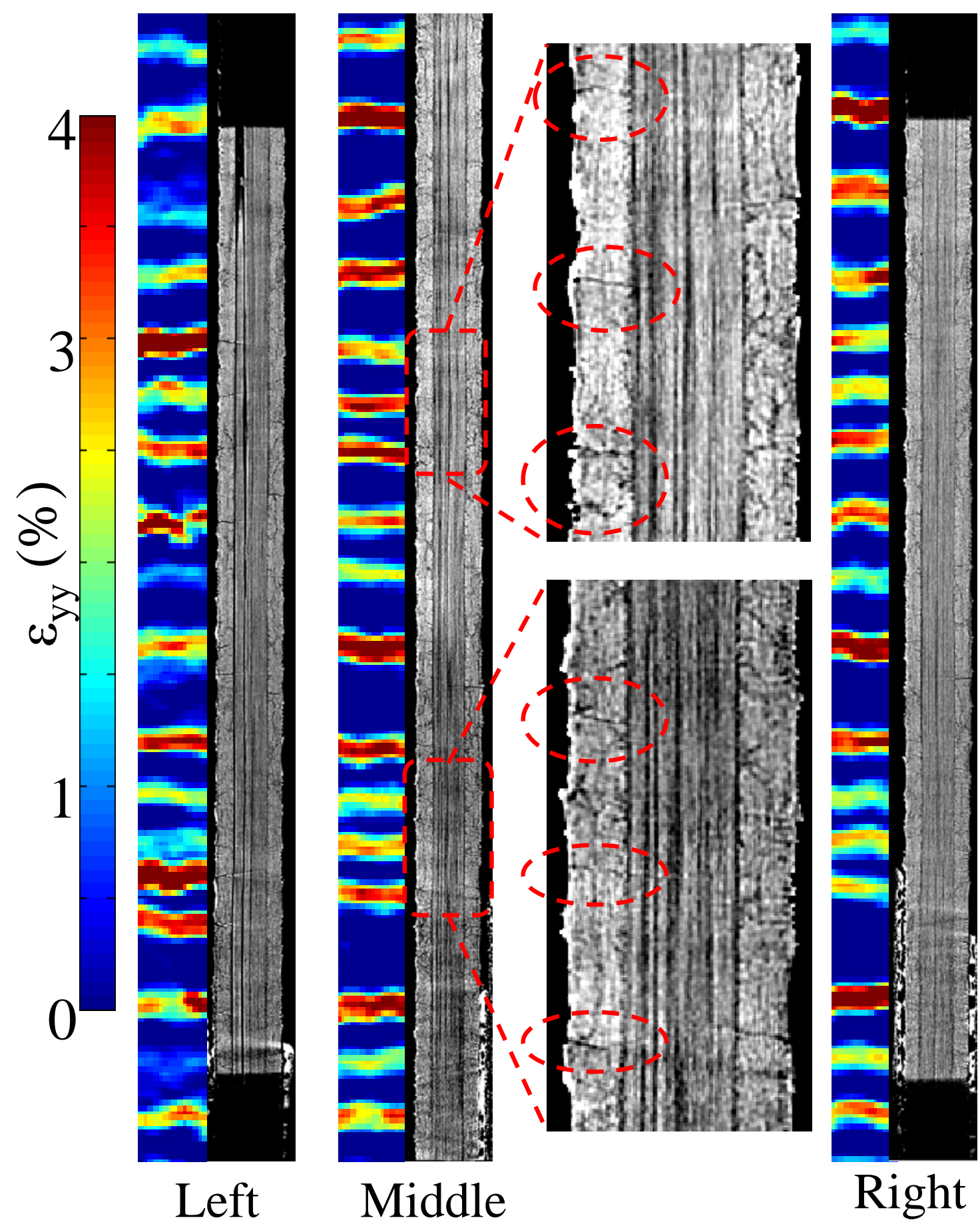

Figure 16: Comparison of DIC longitudinal strain data and vertical (longitudinal) X-ray CT cross sectional images of a fatigued CFRP specimen. A zoomed view of the middle section of the specimen shows the surface cracks in the $90^{\circ}$ ply correspond with the regions of high longitudinal strain shown by the DIC. 


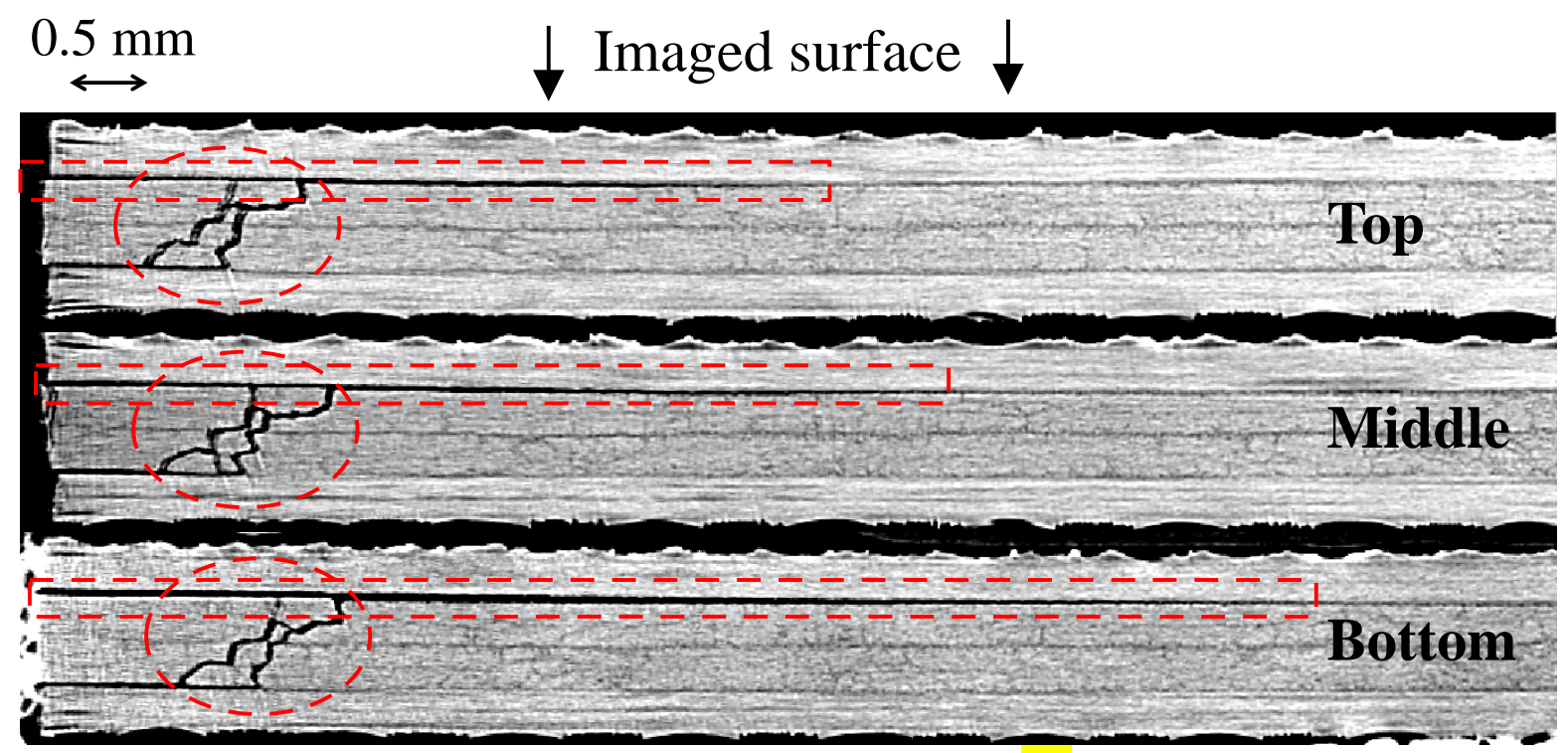

Figure 17: X-ray CT width-wise cross sectional images of the fatigued CFRP specimen. Delaminations and longitudinal splitting are highlighted in red.
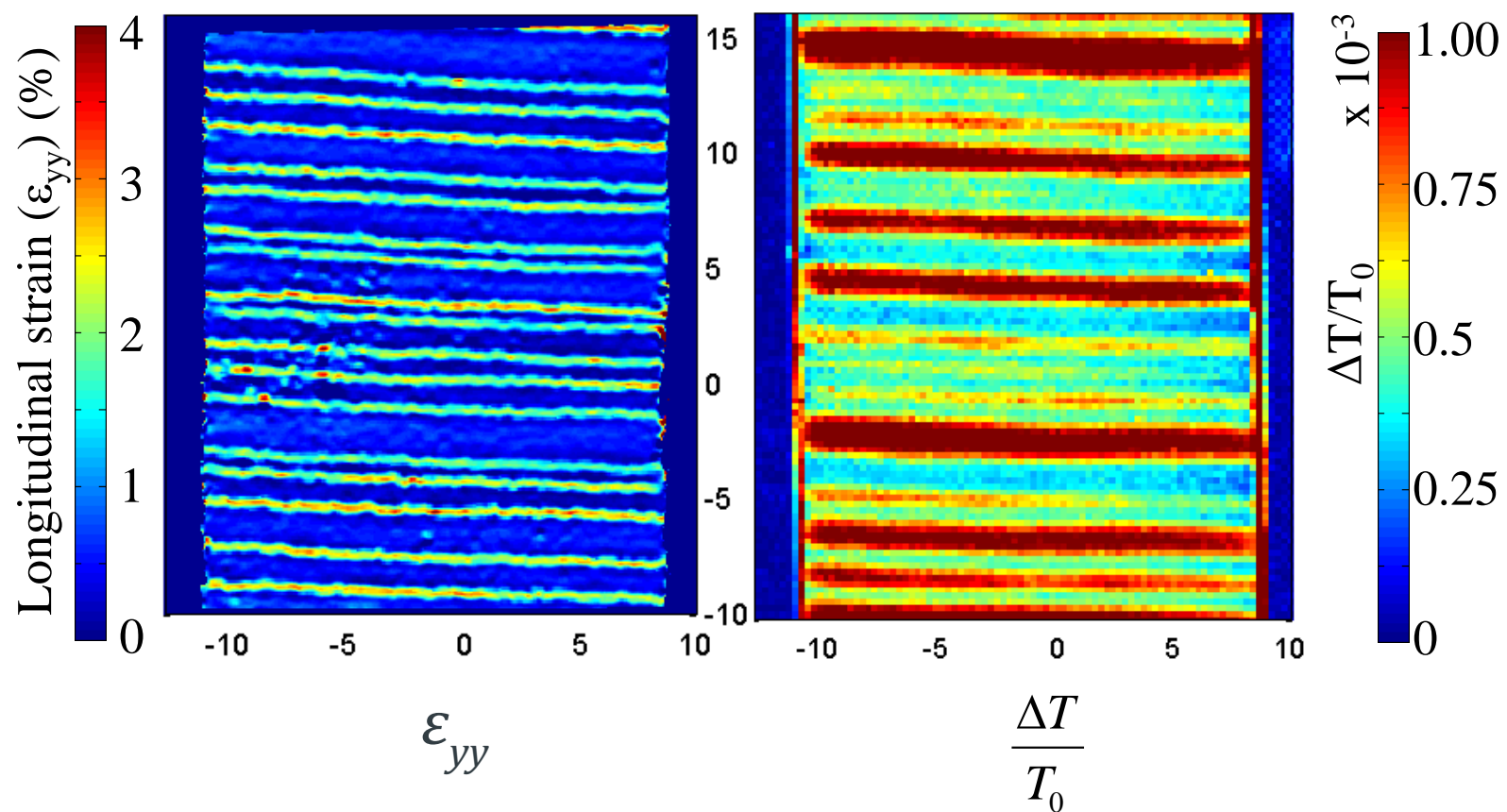

Figure 18: Longitudinal strain $\left(\varepsilon_{y y}\right)$ and normalised thermoelastic response $\left(\Delta T / T_{0}\right)$ at the start of fatigue life of the damaged crossply CFRP specimen. 
G.P.Battams and J.M. Dulieu-Barton, "Data-Rich Characterisation of Damage Propagation in Composite Materials", Composites Part A, 2016, doi:10.1016/j.compositesa.2016.08.007
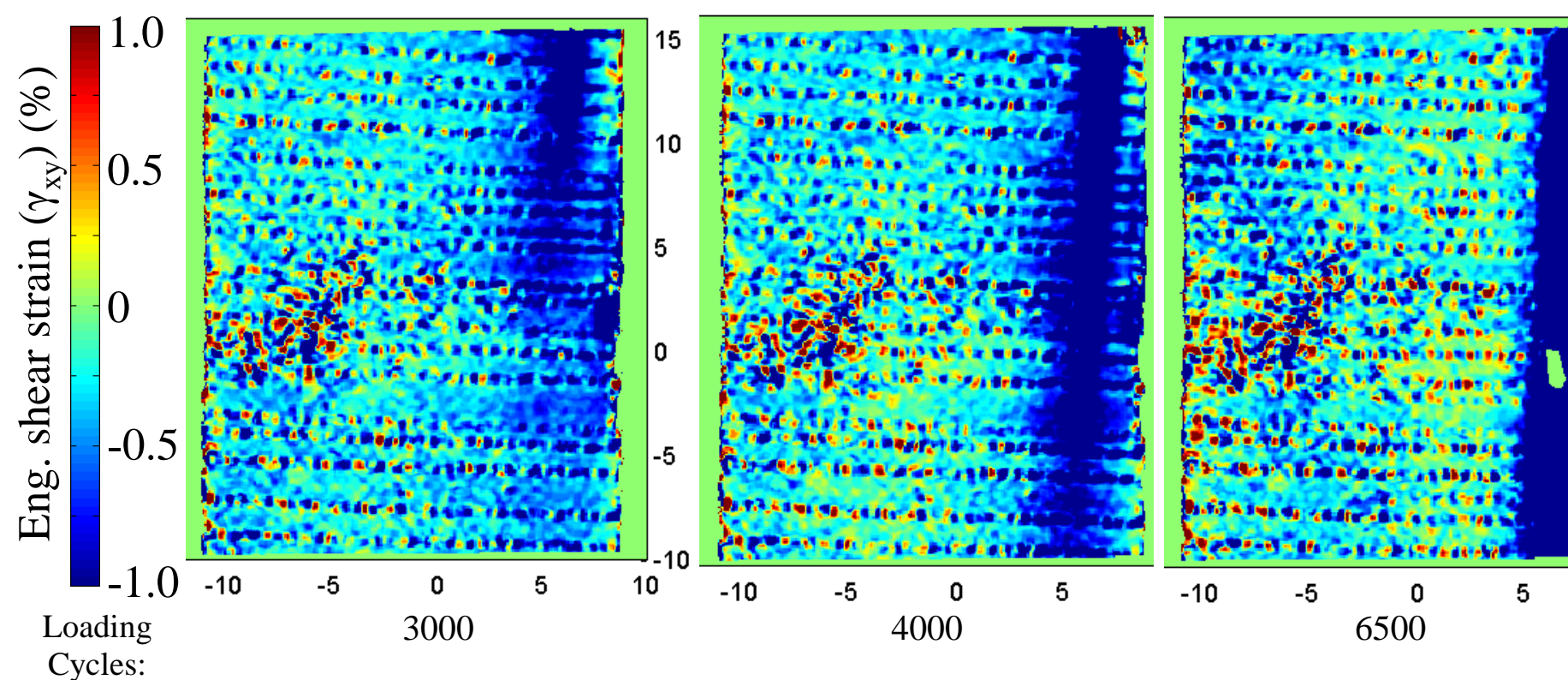

Figure 19: Development of engineering shear strain $\left(\gamma_{x y}\right)$ in the damaged crossply CFRP specimen.
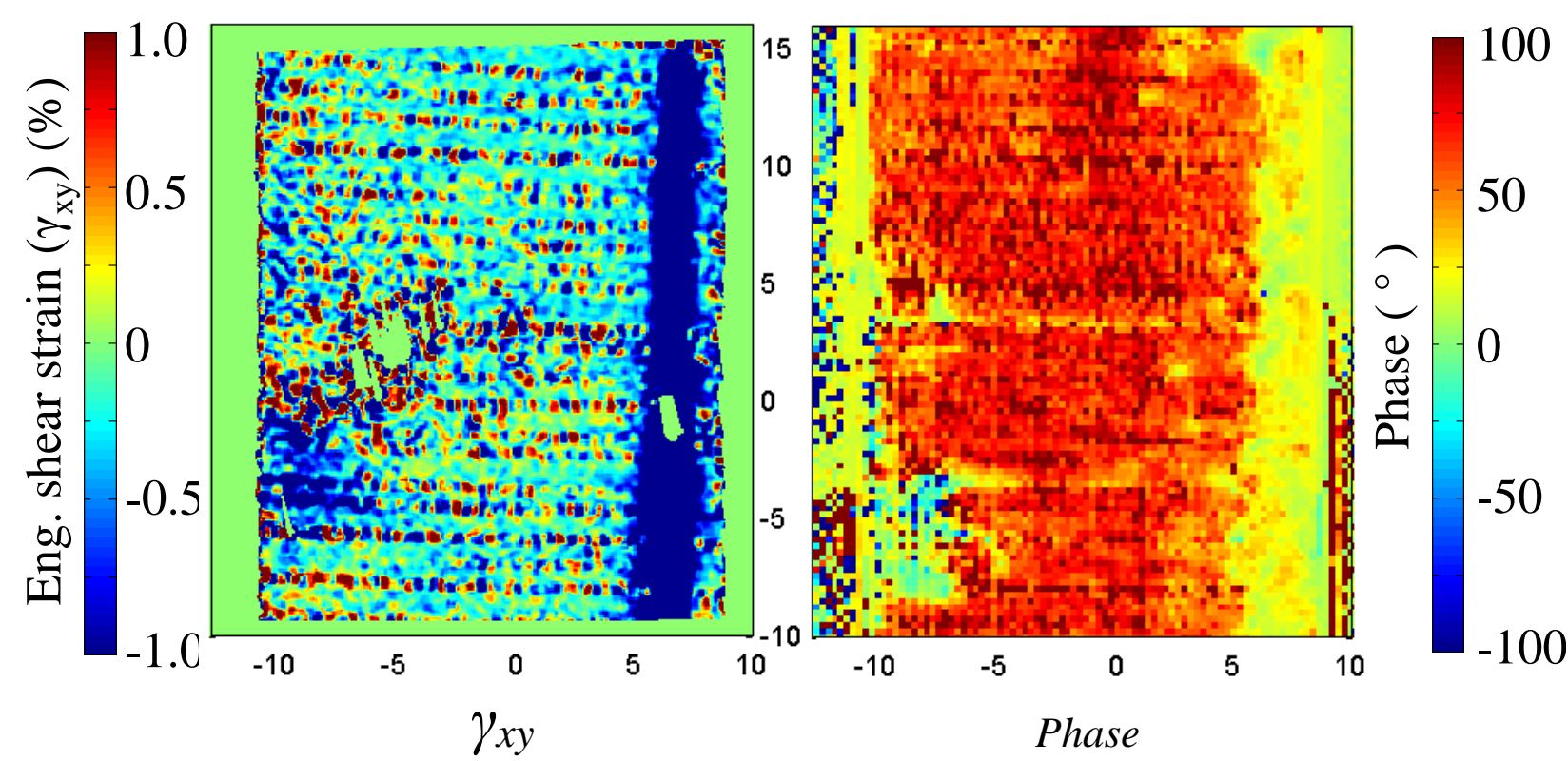

Figure 20: Engineering shear strain $\left(\gamma_{x y}\right)$ and TSA phase data at 240000 loading cycles of the damaged crossply CFRP specimen. 
G.P.Battams and J.M. Dulieu-Barton, "Data-Rich Characterisation of Damage Propagation in Composite Materials", Composites Part A, 2016, doi:10.1016/j.compositesa.2016.08.007
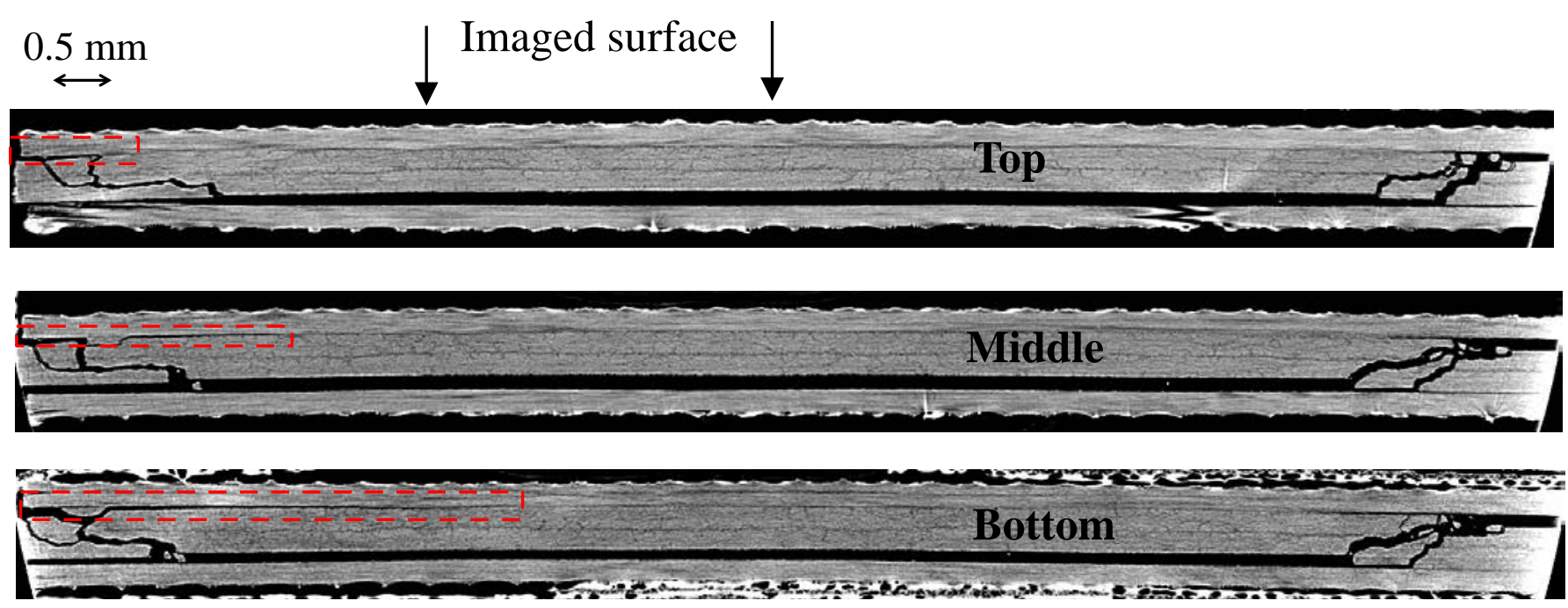

Figure 21: X-ray CT width-wise cross sectional images of the fatigued CFRP specimen previously loaded at intermediate strain rate. Delaminations highlighted in red. 